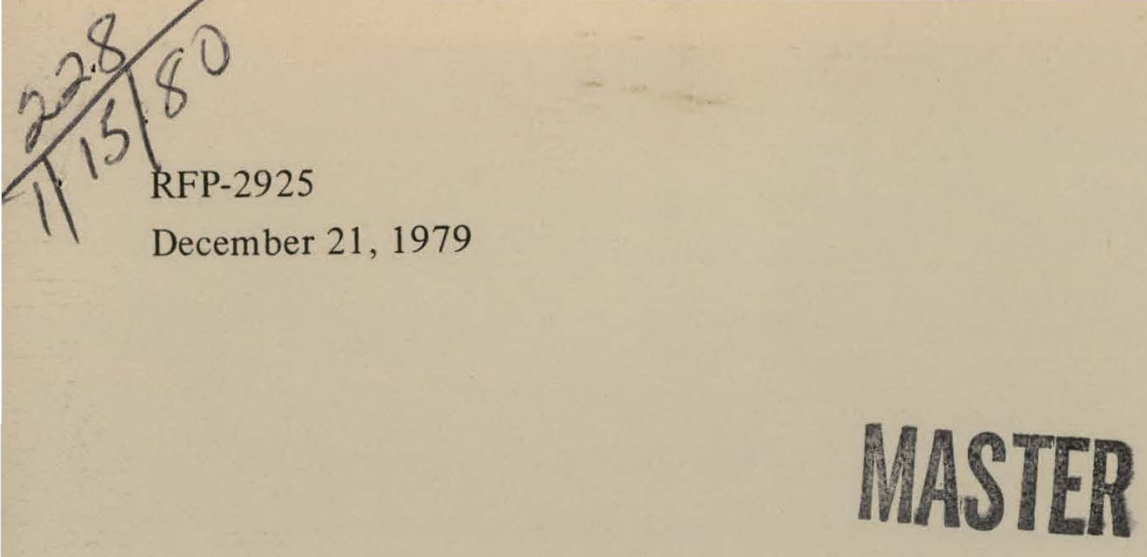

RFP-2925

December 21, 1979

\title{
SEGREGATION EFFECTS IN JBK-75
}

\author{
M. C. Mataya \\ C. M. Edstrom \\ R. W. Krenzer \\ J. H. Doyle
}

\section{Rockwell International}

\author{
Energy Systems Group \\ Rocky Flats Plant \\ P.O. Box 464 \\ Golden, Colorado 80401
}

U. S. DEPARTMENT OF ENERGY

CONTRACT DE-AC04-76DPO3533 


\section{DISCLAIMER}

This report was prepared as an account of work sponsored by an agency of the United States Government. Neither the United States Government nor any agency Thereof, nor any of their employees, makes any warranty, express or implied, or assumes any legal liability or responsibility for the accuracy, completeness, or usefulness of any information, apparatus, product, or process disclosed, or represents that its use would not infringe privately owned rights. Reference herein to any specific commercial product, process, or service by trade name, trademark, manufacturer, or otherwise does not necessarily constitute or imply its endorsement, recommendation, or favoring by the United States Government or any agency thereof. The views and opinions of authors expressed herein do not necessarily state or reflect those of the United States Government or any agency thereof. 


\section{DISCLAIMER}

Portions of this document may be illegible in electronic image products. Images are produced from the best available original document. 


\section{LEGAL NOTICE}

This report was prepared as an account of work sponsored by the United States Government. Neither the United States nor the Department of Energy, nor any of their employees, nor any of their contractors, subcontractors, or their employees, makes any warranty, expressed or implied, or assumes any legal liability or responsibility for the accuracy, completenesss or usefulness of any information, apparatus, product or process disclosed, or represents that its use would not infringe privately owned rights.

Printed in the United States of America

Available from the

National Technical Information Service

U. S. Department of Commcrec

Springfield, Virginia 22161

Price: Printed Copy $\$ 5.00$ Microfiche $\$ 3.00$

Price Is Subject to Change Without Notice 
Printed

December 21, 1979
RFP-2925

UC-25 MATERIALS

TID-4500 (Rev. 67) MASTER

\section{SEGREGATION EFFECTS IN JBK-75}

M: C. Malaya

C. M. Edstrom

R. W. Krenzer

J. H. Doyle

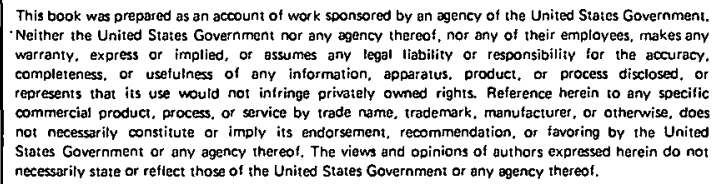

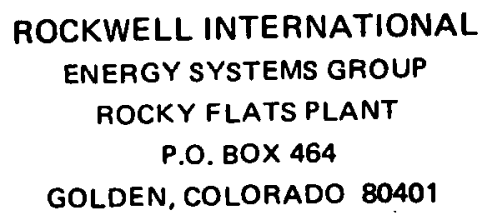

Prepared under Contract DE-AC04-76DPO3533

for the

Albuquerque Operations Office

U.S. Department of Fnerov. 
RFP-2925

\begin{abstract}
A C K N O W LED G M E N T S
The authors are indebted to J. H. Doyle of the Physical Metallurgy Group at Rocky Flats for providing the microprobe analyses for this work. The authors would like to credit Carlo Peper for the development of a polarized light technique to rate the degree of titanium segregation.
\end{abstract}




\section{CONTENTS}

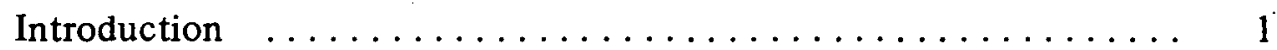

Analysis of Titanium Segregation $\quad \ldots \ldots \ldots \ldots \ldots \ldots \ldots \ldots \ldots \ldots$

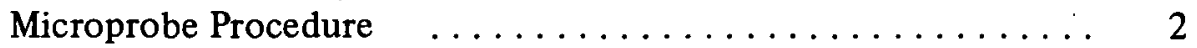

Microprobe Data Observations $\ldots \ldots \ldots \ldots \ldots \ldots \ldots \ldots \ldots$

Metallography $\ldots \ldots \ldots \ldots \ldots \ldots \ldots \ldots \ldots \ldots \ldots \ldots \ldots \ldots \ldots$

Controlling Segregation $\ldots \ldots \ldots \ldots \ldots \ldots \ldots \ldots \ldots \ldots \ldots \ldots \ldots$

Improvements by the Mill $\ldots \ldots \ldots \ldots \ldots \ldots \ldots$

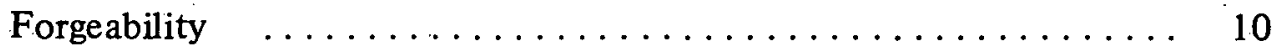

Reduction of Titanium

Segregation Through Homogenization $\ldots \ldots \ldots \ldots \ldots \ldots \ldots$

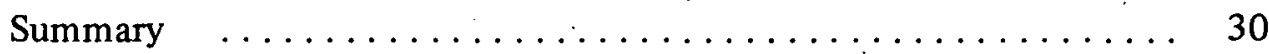

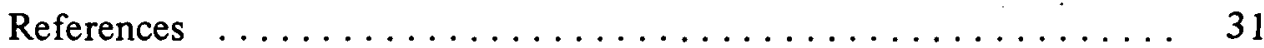


RFP-2925 
RFP-2925

\title{
SEGREGATION EFFECTS IN JBK-75
}

\author{
M. C. Mataya, C. M. Edstrom, R. W. Krenzer, and J. H. Doyle
}

\begin{abstract}
Banding or chemical segregation of alloying elements, can be a severe problem in complex alloys. Many problems have been experienced with developing fabrication processes for JBK-75 and it is suggested that these difficulties may be related in part to the degree of chemical heterogeneity that exists in the alloy. Early testing and qualification of the alloy was made on relatively homogeneous samples, which came from small diameter ingots. However, in larger size ingots used for production, it is more difficult to achieve a uniform distribution of alloying elements in the product. This can result in greater variability of alloy properties which are, in most cases, difficult to explain.
\end{abstract}

Extensive microprobe measurements were made on samples of JBK-75 bar stock from several different production size ingots. It was found that segregation of titanium is a common occurrence. Titanium banding can be controlled by ingot melting rate and homogenization of ingot or intermediate product. A model for titanium diffusion shows that homogenizing at the ingot stage is ineffectual willi tespect to the spacing measured in this report. However, homogenizing 20.3-cm diameter intermediate product, where band spacing is reduced, will significantly reduce segregation. The effect of segregation on tensile properties is discussed.

Segregation may have a significant influence on forgeability of JBK-75. Forgeability tests show that microstructure plays an important role in the ability of JBK-75 to deform homogeneously, and microstructure is controlled by chemical uniformity of the alloy. Inhomogeneous shear during forging can cause adiabatic shear planes to form, and these have been observed in JBK-75.

\section{INTRODUCTION}

Design requirements in recent years have emphasized the need for higher strength, stable austenitic steels for certain applications. The search for a stainless steel in which yield strengths of at least $896 \mathrm{MN} / \mathrm{m}^{2}$ (130 ksi) could be readily obtained led to an extensive program culminating in the development of a new alloy designated JBK-75. This new alloy is similar to A-286, an iron-based super-alloy, with slight chemistry modifications to improve weldability and performance of the alloy in certain environments. Initial qualification on the performance of the alloy was made on samples from small experimental heats, and the alloy was shown to possess desired properties for intended applications.

Subsequent development of the alloy was directed towards obtaining combined strain and age hardening by both high energy rate forging and press forging to reach $896 \mathrm{MN} / \mathrm{m}^{2}$ yield strength levels. However, difficulties in achieving uniform strengths and frequent occurrence of forging defects required numerous modifications of die design and forging practice during development. It was also found that to control grain size in forgings and avoid detrimental second phases and forging defects, the hot working temperature range had to be limited to $965-995^{\circ} \mathrm{C}$.

The problems experienced with developing a forging process for JBK-75 suggest that we do not fully understand the behavior of the alloy. Many factors contribute to forgeability (the ability of a metal to flow and fill a closed-die cavity without forming defects or initiating some form of fracture in the forging). In addition, factors which control final mechanical properties of the forging may depend upon the same characteristics which control forgeability. It is suspected that segregation of alloy elements, or banding, in JBK-75 may be a major factor in determining forgeability and the ability to achieve uniform mechanical properties and desired metallurgical characteristics in forgings. Banding is typical in alloys like A-286 or JBK-75, and becomes more severe with larger ingot sizes. Thus, desired properties and fabrication characteristics observed on small experimental ingots may be substantially altered in product from 
larger production ingots. While the origins of banding due to the solidification process are reasonably understood, the effect of banding on forgeability and mechanical properties is not clear. Since banding is a significant characteristic of JBK-75, it is reasonable to investigate the extent of alloy segregation that has occurred in typical product and determine if difficulties experienced with JBK- 75 can be explained by the presence of banding.

Extensive microprobe measurements have been made on several heats of JBK-75 bar stock to characterize banding in the alloy. This report deals with the extent of banding found in the alloy, together with discussions on minimizing segregation in JBK-75. Consideration is given to homogenization of ingot product, and a mathematical model for titanium diffusion and segregation in JBK-75 is presented.

\section{ANALYSIS OF TITANIUM SEGREGATION}

Detailed microprobe analysis has established that all production heats of JBK-75 received at Rocky Flats contain titanium segregation. In severe cases, the titanium content can vary as much as one weight percent (refer to Table 1). Since JBK-75 is used in critical applications, it is important to characterize typical product.

\section{Microprobe Procedure}

Analysis of titanium segregation was performed on a Cameca microprobe, the Camebax model. The probe is coupled with a computer which controls the movement of the sample stage and counting time. It also collects and correlates data simultaneously, which greatly increases the speed of analysis. These features permit examination of up to three samples per day.

The machine has three crystal analyzers. In the analysis of the JBK-75 samples, one crystal analyzer gathered data on titanium and a second analyzer determined the iron, nickel, and chromium chemistry.
The procedure for analyzing each sample involved initially scanning across the sample in a direction perpendicular to the axis of the $12.7-\mathrm{cm}$ diameter rod. Each sample examined came from the midradius section of the bar. The length of scan was generally 15 millimeters. A qualitative plot of the titanium distribution was obtained by taking point measurements every 30 microns. From this plot, a region in the sample was selected to provide a representative area for quantitative analysis.

The quantitative analysis was made by analyzing the $x$-ray wavelength. A series of seventy-one measurements at 30 micron spacing was made over a 2.1-millimeter length. Experimental data are provided by both numerical and graphical output. In making the graph; a three point smoothing technique was used to plot the curve. In the actual analysis of the data, titanium contents over $4 \mathrm{wt} \%$ were disregarded since the higher titanium values were probably due to some type of titanium inclusion.

\section{Microprobe Data Observations}

Several points need to be emphasized concerning the microprobe data in Table 1. The experimental heats, (E), cast as 5-inch diameter ingot, all have one sigma standard deviation values of $\pm 0.15 \%$ titanium or less. The only production heats which display similar titanium segregation are Heats 7683 and 94888 . Heat 7683 has acceptable titanium distribution because it received a double homogenization treatment, homogenizing at both the ingot size and intermediate 8-inch bloom. The reason for good distribution in Heat 94888 is unknown. It received the same homogenization treatment as Heats 96604 and 96606 and was produced by the same supplier. Casting practices should have been the same for Heats 94888, 96604, and 96606 . Thus, the extent of segregation in single homogenized heats appears to be somewhat random.

Table 1 also includes the titanium segregation results on samples from $12.7-\mathrm{cm}$ diameter bar, which were homogenized for 160 hours at $1180^{\circ} \mathrm{C}$. The $926 \mathrm{SH}$ and $94888 \mathrm{SH}$ (super-homogenized) samples when 
TABLE 1. Titanium Segregation

\begin{tabular}{|c|c|c|c|c|c|c|c|c|c|}
\hline $\begin{array}{l}\text { Heat } \\
\text { No. }\end{array}$ & $\begin{array}{l}\text { Sample } \\
\text { No. }\end{array}$ & $\begin{array}{c}\mathrm{Ti} \\
\text { Mean }\end{array}$ & $\begin{array}{c}1 \\
\text { Sigma } \\
\end{array}$ & $\begin{array}{l}\text { Absolute } \\
\text { Range }\end{array}$ & $\underline{\Delta \mathrm{Ti}}$ & $\begin{array}{l}\text { Graph } \\
\text { Range } \\
\end{array}$ & $\Delta \mathrm{Ti}$ & Points & Remarks \\
\hline 93491 & 93491F & 2.12 & 0.26 & $1.62-2.58$ & 0.96 & $2.50-1.50$ & 1.00 & 71 & No Homogenization \\
\hline 94888 & $\begin{array}{l}94888 F \\
105622\end{array}$ & $\begin{array}{l}2.05 \\
2.06\end{array}$ & $\begin{array}{l}0.11 \\
0.09\end{array}$ & $\begin{array}{l}1.85-2.48 \\
1.86-2.34\end{array}$ & $\begin{array}{l}0.63 \\
0.48\end{array}$ & $\begin{array}{l}2.30-1.90 \\
2.30-1.90\end{array}$ & $\begin{array}{l}0.40 \\
0.40\end{array}$ & $\begin{array}{l}71 \\
71\end{array}$ & \\
\hline 96604 & $\begin{array}{l}106044 \\
106047 \\
106051 \\
106056\end{array}$ & $\begin{array}{l}2.07 \\
2.09 \\
1.96 \\
2.07\end{array}$ & $\begin{array}{l}0.28 \\
0.30 \\
0.26 \\
0.26\end{array}$ & $\begin{array}{l}1.66-2.66 \\
1.57-2.73 \\
1.53-2.64 \\
1.66-2.86\end{array}$ & $\begin{array}{l}1.00 \\
1.16 \\
1.11 \\
1.20\end{array}$ & $\begin{array}{l}2.55-1.70 \\
2.70-1.60 \\
2: 50-1.55 \\
2.70-1.70\end{array}$ & $\begin{array}{l}0.85 \\
1.10 \\
0.95 \\
1.00\end{array}$ & $\begin{array}{l}71 \\
71 \\
71 \\
71\end{array}$ & \\
\hline 96606 & $\begin{array}{l}105885 \\
105886 \mathrm{C} 1 \\
105886 \mathrm{C} 2\end{array}$ & $\begin{array}{l}2.10 \\
2.04 \\
2.10\end{array}$ & $\begin{array}{l}0.30 \\
0.17 \\
0.17\end{array}$ & $\begin{array}{l}1.45-2.67 \\
1.65-2.38 \\
1.75-2.49\end{array}$ & $\begin{array}{l}1.22 \\
0.73 \\
0.74\end{array}$ & $\begin{array}{l}2.60-1.50 \\
2.40-1.80 \\
2.35-1.75\end{array}$ & $\begin{array}{l}1.10 \\
0.60 \\
0.60\end{array}$ & $\begin{array}{l}71 \\
71 \\
71\end{array}$ & . \\
\hline 926 & $926 \mathrm{~F}$ & 2.36 & 0.29 & $1.98-3.90$ & 1.92 & $3.30-2.10$ & 1.20 & 71 & \\
\hline 7683 & $\begin{array}{l}\text { 7683DH } \\
\text { (MR-Forge) } \\
\text { 7683DH } \\
7683 \mathrm{~N}-\mathrm{F}\end{array}$ & $\begin{array}{l}1.95 \\
2.03\end{array}$ & $\begin{array}{l}0.14 \\
0.11 \\
0.20\end{array}$ & $\begin{array}{l}1.77-2.17 \\
1.69-2.62\end{array}$ & $\begin{array}{l}0.40 \\
0.93\end{array}$ & $\begin{array}{l}2.50-1.86 \\
2.20-1.80 \\
2.40-1.70\end{array}$ & $\begin{array}{l}0.40 \\
0.70\end{array}$ & $\begin{array}{r}71 \\
42 \\
71\end{array}$ & Double Homogenized \\
\hline $\mathbf{E}$ & $\begin{array}{l}5267 \\
5279 \\
5264 \\
5297\end{array}$ & $\begin{array}{l}1.90 \\
1.96 \\
2.09 \\
2.47\end{array}$ & $\begin{array}{l}0.07 \\
0.08 \\
0.07 \\
0.15\end{array}$ & $\begin{array}{l}1.80-3.13 \\
1.81-2.29 \\
1.95-2.36 \\
2.23-3.13\end{array}$ & $\begin{array}{l}0.33 \\
0.48 \\
0.41 \\
0.90\end{array}$ & $\begin{array}{l}2.00-1.80 \\
2.12-1.86 \\
2.30-2.00 \\
2.70-2.25\end{array}$ & $\begin{array}{l}0.20 \\
0.26 \\
0.30 \\
0.45\end{array}$ & $\begin{array}{l}71 \\
71 \\
71 \\
71\end{array}$ & Cast 385 in. Dia. Ingot \\
\hline 926 & $926 \mathrm{SH}$ & 2.38 & 0.03 & $2.31-2.47$ & 0.16 & $\ldots$ & $\ldots$ & 71 & $\begin{array}{l}\text { Super Homo- } 160 \mathrm{hrs} \\
\text { at } 1180^{\circ} \mathrm{C} \text { at } 5 \text { in Dia. }\end{array}$ \\
\hline 94888 & $94888 \mathrm{SH}$ & 2.12 & 0.03 & $2.07-2.18$ & 0.11 & $\ldots$ & $\ldots$ & 71 & $\begin{array}{l}\text { Super Homo- } 160 \text { hrs } \\
\text { at } 1180^{\circ} \mathrm{C} \text { at } 5 \text { in Dia. }\end{array}$ \\
\hline M29 & $\begin{array}{r}\text { Sandia } \\
\text { Alb. }\end{array}$ & 2.17 & 0.17 & $1.77-2.72$ & 0.95 & $2.52-1.84$ & $\ldots$ & 71 & 4200 Amp Melting Rate \\
\hline M30 & $\begin{array}{l}\text { Sandia } \\
\text { Alb. }\end{array}$ & 2.30 & 0.12 & $2.01 \cdot 2.58$ & 0.57 & $2.55-2.10$ & $\cdots$ & 71 & 3000 Amp Melting Rate \\
\hline
\end{tabular}




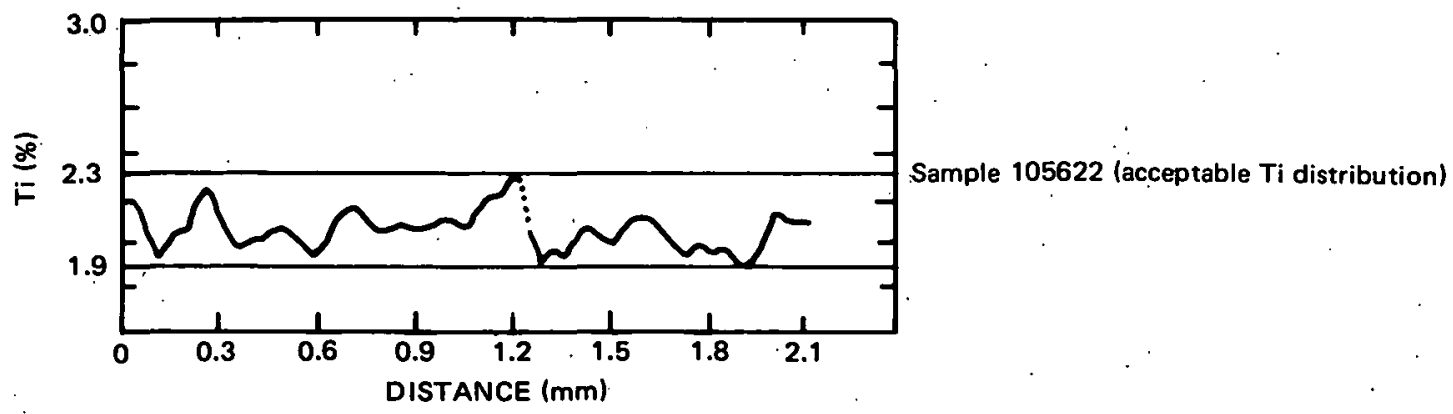

Sample 106047 (unacceptable Ti distribution)

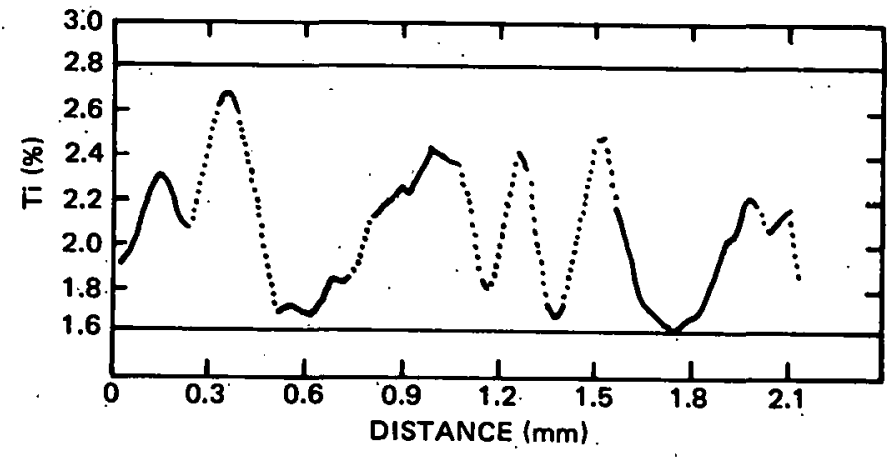

FIGURE 1. Titanium Trace Produced by Microprobe

analyzed by the microprobe for titanium segregation were essentially free of segregation; i.e., a one sigma of $0.03 \%$ titanium or less. Super-homogenized. in this report refers to the longtime (160 hours) treatment at $1180^{\circ} \mathrm{C}$.

Figure l compares the microprobe traces for Samples No. 105622 (acceptable titanium segregation) and No. 106047 (undesirable titanium segregation). These traces show that the band spacing of high and low titanium in the $12.7-\mathrm{cm}$ diameter bar range from 0.2 to $0.3 \mathrm{~mm}$. Band spacing is required for calculating the homogenization time required to diffuse the titanium and produce a more chemically homogeneous distribution. (See section on homogenization.)

\section{Metallography}

Attempts have been made to correlate measured titanium segregation with metallography because microprobe analysis is not readily adaptable, because of time limitations, to acceptance testing for bar product.

Observations made on polished samples show a trend between microcleanliness and segregation. Reduced titanium segregation results in fewer titanium sulfide and titanium carbonitride inclusions. Figure 2 illustrates this relationship.

Another method to detect heavy titanium segregation involves ASTM E-407 Etch No. 107 and - polarized light. With this etch (10\% phosphoric, $50 \%$ sulfuric, and $40 \%$ nitric acid) and polarized light, the samples confirmed to be high in titanium segregation display banding. Figure 3 illustrates the type of banding seen in samples after the electrolytic etch.

To verify that the banding seen in the electrolytically etched metallographic samples represents variation 
RFP-2925

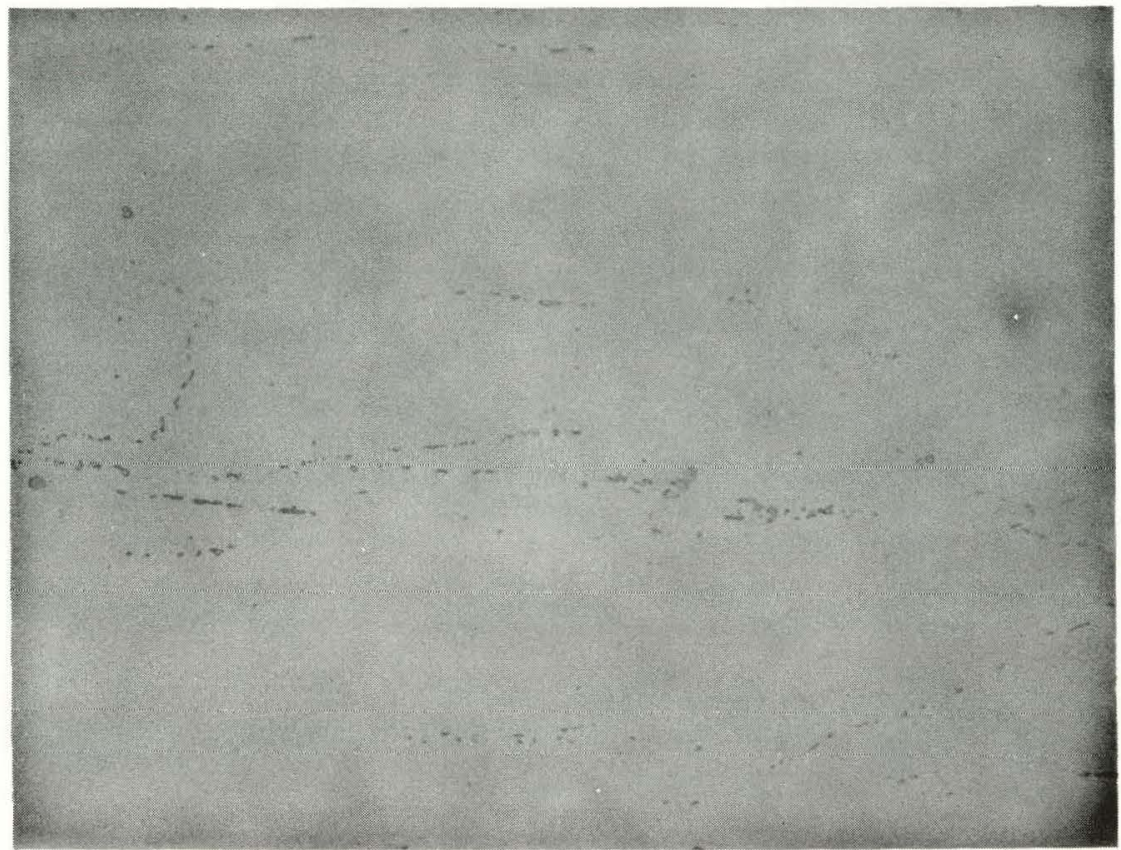

Sample 105622 (acceptable Ti segregation)

$100 x$

Sample 106047 (unacceptable Ti segregation)

$100 x$

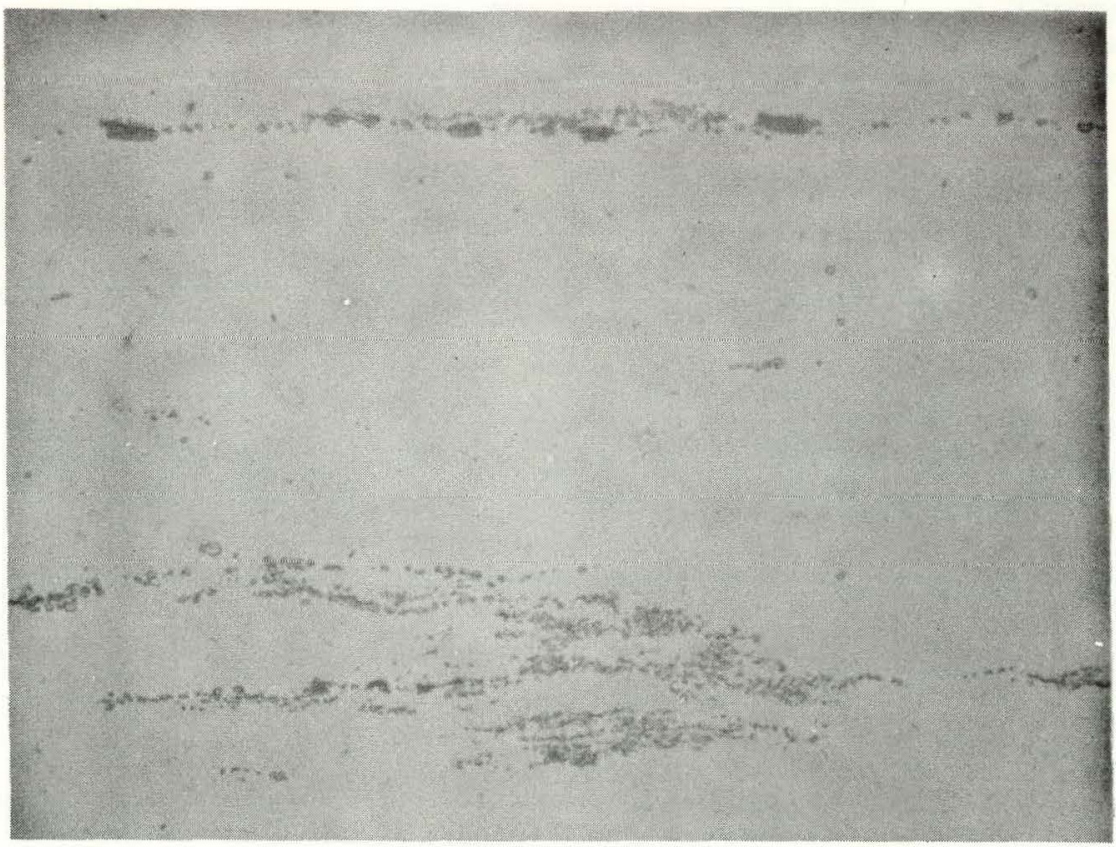

FIGURE 2. Polished Micrograph Highlighting Inclusions 
RFP-2925

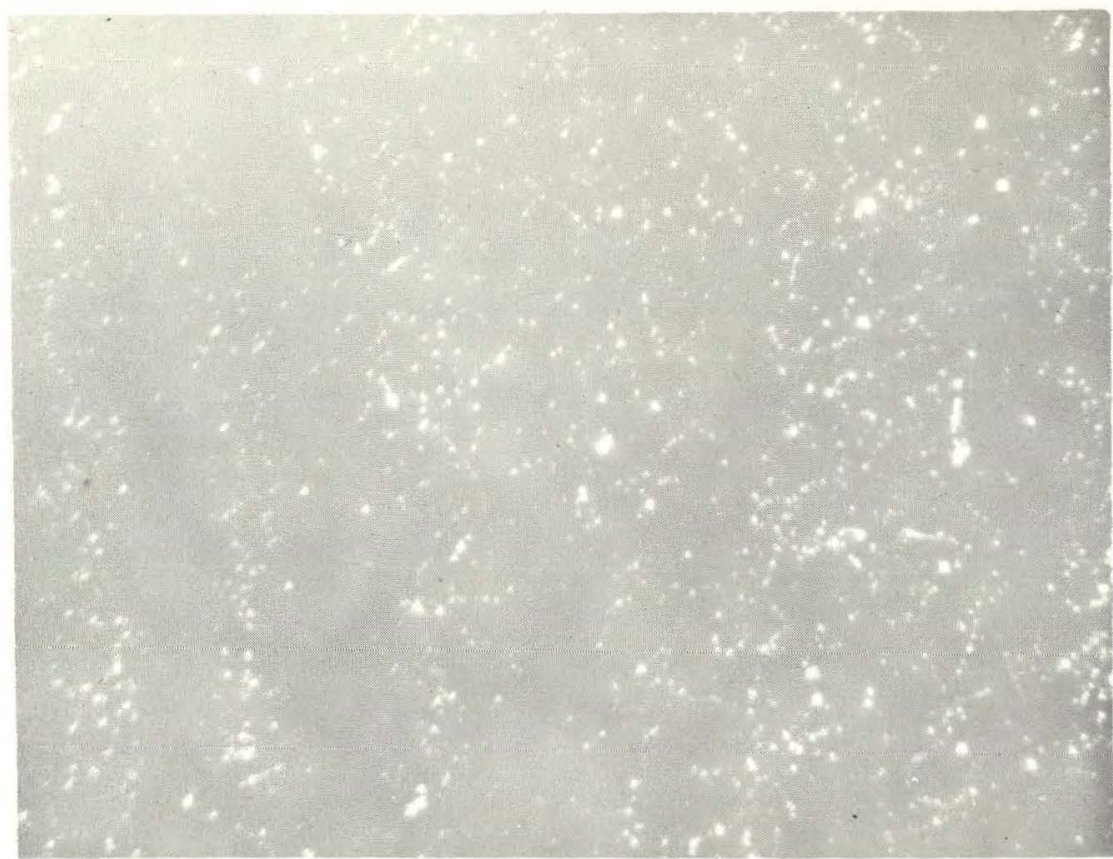

Sample 1058881 Sigma $0.10 \% \mathrm{Ti}$

$100 x$

(acceptable titanium segregation)

Etch: ASTM E-407, Etch No. 107

Sample 7683-NF 1 Sigma 0.20\% Ti

(moderate titanium segregation)

Etch: ASTM E-407, Etch No. 107

$100 x$

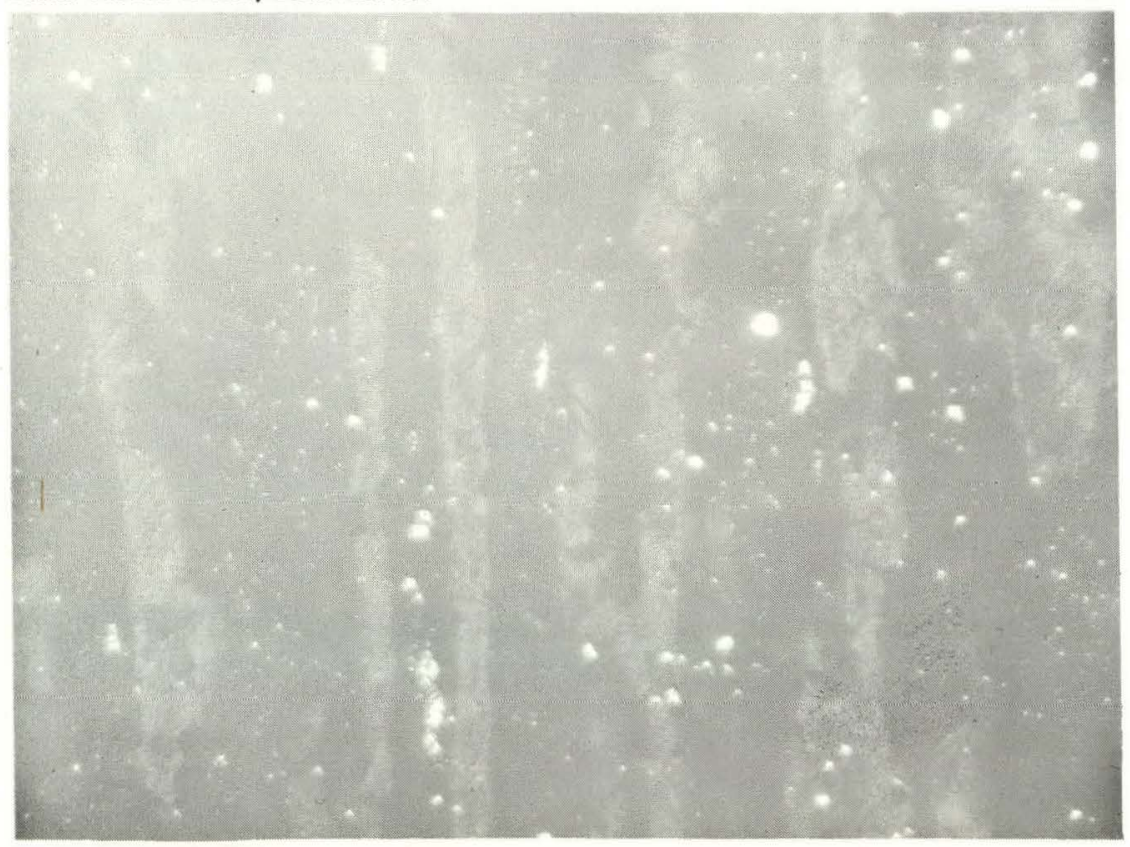

FIGURE 3. Banding Highlight With

Electrolytic Etch and Polarized Light 
RFP-2925

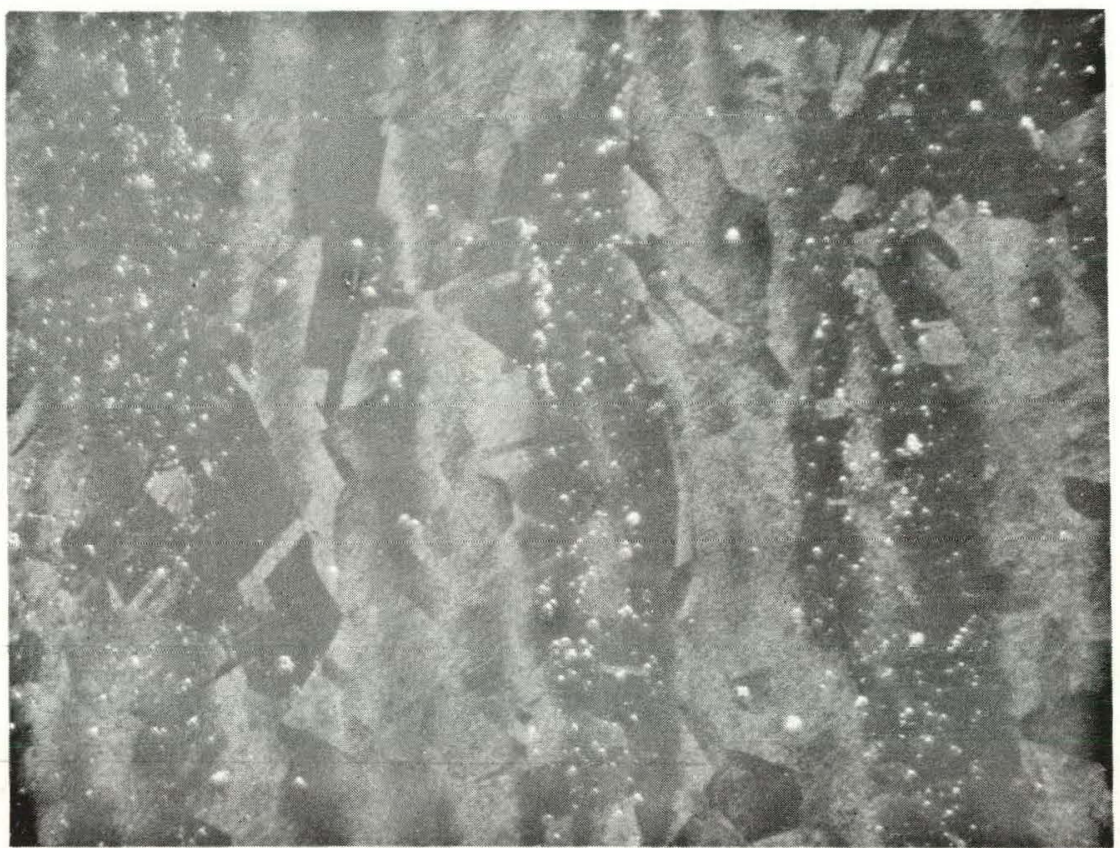

Semple 1060511 Sigma 0.28\% Ti

$100 x$

(undesirable titanium segreqation)

Etch: ASTM E-407, Etch No. 107

FIGURE 3 (Concluded). Banding Highlight With Electrolytic Etch and Polarized Light 
RFP-2925

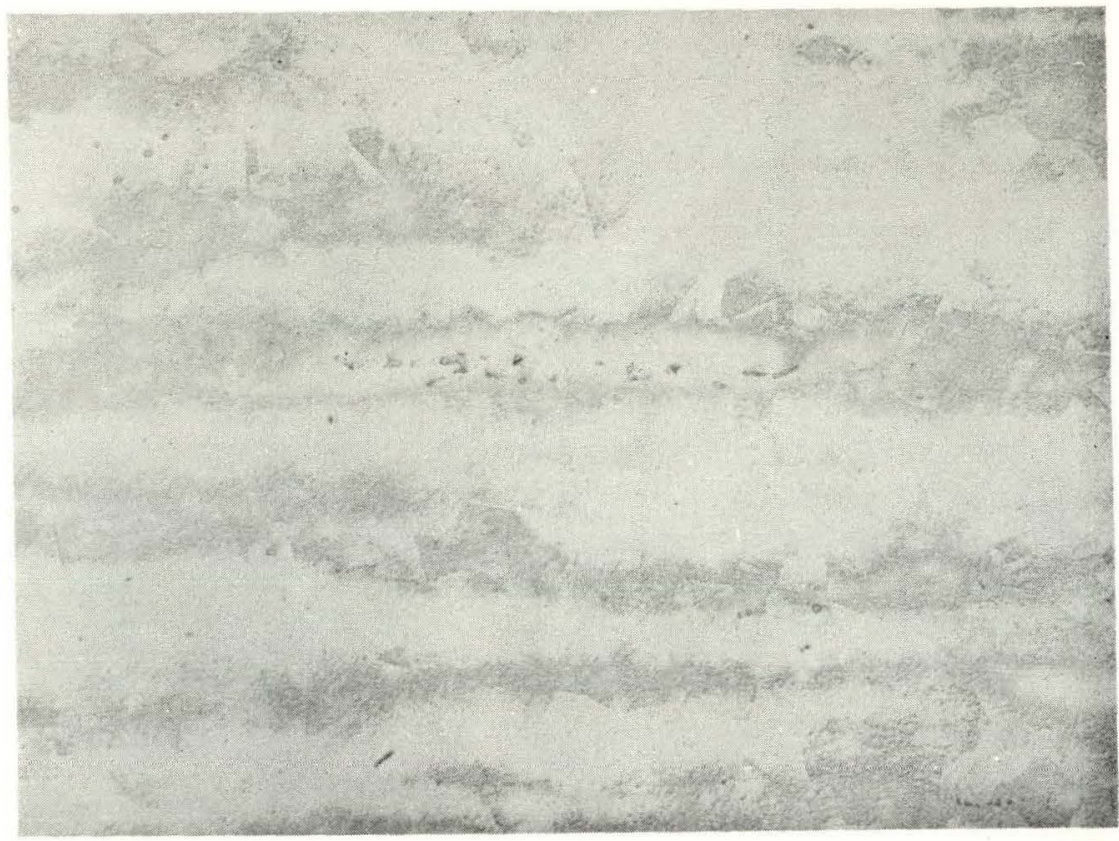

Sample 106047 General appearance of

$100 x$

banding after the ASTM E-407, Etch No. 107

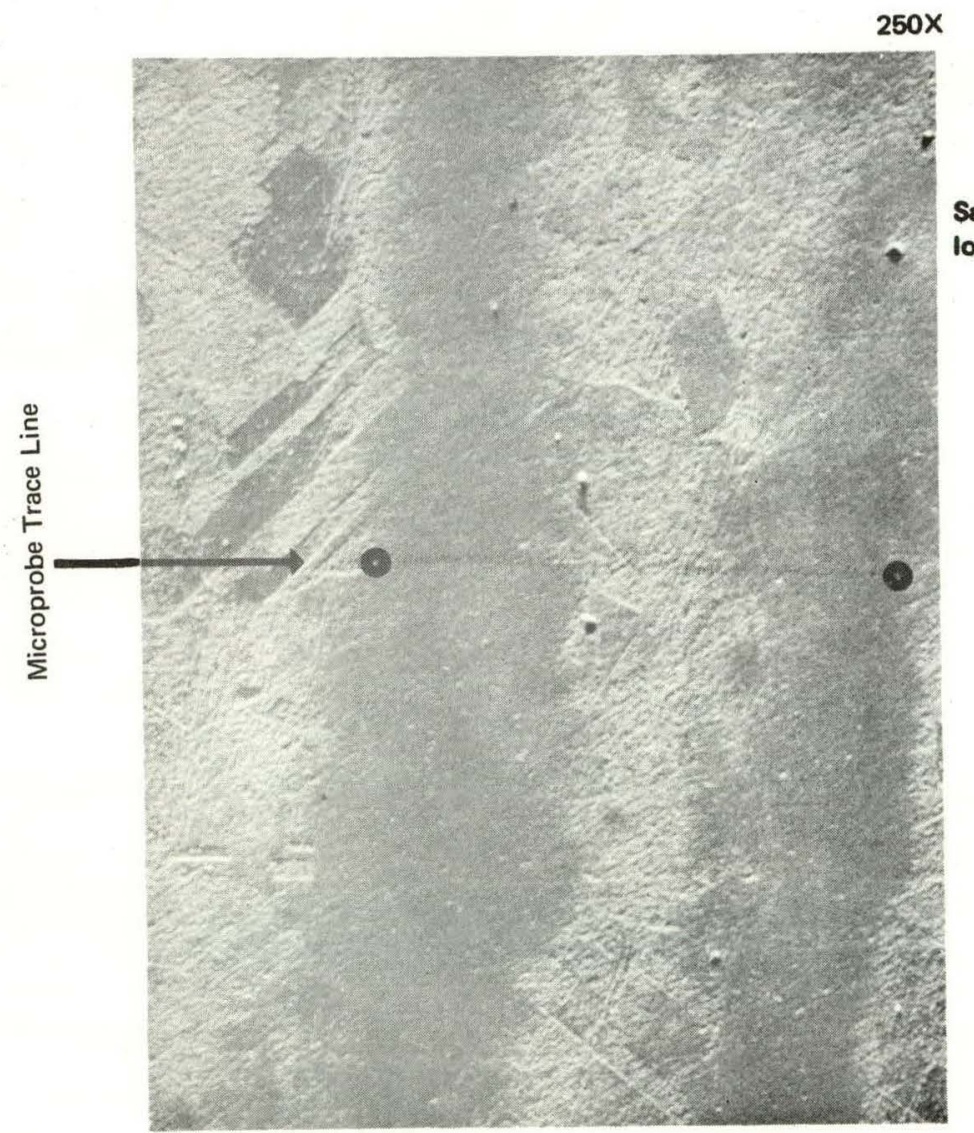

Sample 106047 Results of microprobe trace on titanium concentration.

Note: dark bands are lower in percent $\mathrm{Ti}$

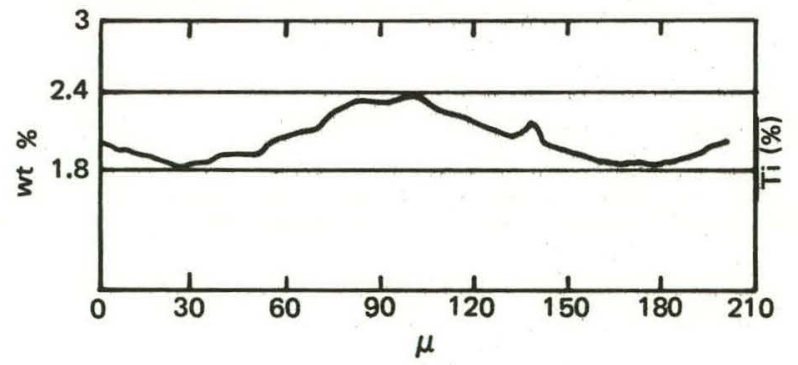

FIGURE 4. Microprobe Analysis of Titanium Across Microetched Bands of Sample No. 106047 
in concentrations of titanium, a microprobe scan was made on sample No. 106047. The results are illustrated in Figure 4. The dark area of the bands correlate to lower titanium and the light areas to higher titanium concentration. This particular sample has been analyzed for titanium distribution twice (refer to Figures 1 and 4). These two analyses do not give the same results because the basis for where microprobe scan was located are different. The first analysis was designed to look at areas of maximum titanium variation and the second scan was to analyze the bands highlighted metallographically.

\section{CONTROLLING SEGREGATION}

\section{Improvements by the Mill}

Discussions about the excessive titanium segregation with four suppliers: Cartech, Simonds, Special Metals, and Allvac, provided several possible ways to improve the titanium distribution:

1. Slow the melting rate because it effectively increases the cooling rate during the VAR ingot casting.

2. Incorporate an ESR (Electroslag Remelt) or air melt plus AOD (Argon-Oxygen Decarbonization) prior to VAR casting to reduce the sulfides and carbides.

3. Cast $30.5-\mathrm{cm}$ diameter ingots instead of 40.6-cm diameter.

4. Homogenize at an intermediate stage.

The last two suggestions are the least desirable for the steel producer. Only one supplier suggested casting the $30.5-\mathrm{cm}$ diameter and to do so only as a last resort because of poor metal recovery.

Increasing the homogenization time is not popular with the suppliers for several reasons:

1. Effectiveness is questioned. (However, we have demonstrated that it is effective when band spacing is brought closer together by reducing stock cross-section).

2. Homogenizing at a bloom size smaller than 12 inches does not allow sufficient hot work for complete recrystallization to achieve specified grain size requirements for the 12.7 $\mathrm{cm}$ and $15.2 \mathrm{~cm}$ diameter bars.

3. Longer homogenization ties up furnaces longer, presenting a production bottleneck.

Titanium segregation data generated from samples of two heats of JBK-75 cast at Sandia Albuquerque show that slower VAR melting rate does improve the titanium uniformity. Both heats were cast as eight-inch diameter ingots, Heat M29 was cast at 4200 amps (fast melting rate), and Heat M30 at 3000 amps (slow melting rate). Heat M30 (lower melting rate) showed better titanium distribution (refer to Table 1). Also samples from Heat M29 displayed more banding after the ASTM E-407 No. 107 Etch than M30.

Many of the suppliers suggested that nonmetallic inclusions originate during vacuum induction melting. Two suppliers suggested using ESR as a melting step to minimize inclusions. A third supplier stated that air melt followed by AOD should replace the VIM. This practice is used for making A-286 when material cleanliness is extremely important.

None of the suppliers stated that a slower melting rate for the VAR would cure the titanium segregation but two felt strongly that this change would help. As a user desiring less titanium segregation, it is felt that the best, and possibly only, way to improve the titanium distribution is to rely on the steel vendors to reduce their melting rate during VAR casting. If this fails to reduce the titanium segregation, it is necessary to homogenize the bar and refine the grain size through forging. The grain size requirement in the bar is there for ultrasonic inspection. However, ultrasonic inspection can be performed before homogenization at an intermediate bar size.

Altering the melting practice to include ESR or an $A O D$ process is too speculative to risk the high 
RFP-2925

cost of verifying an improvement in titanium distribution. Casting smaller ingots is also not a viable solution because it limits production of the metal to one supplier who is reluctant to use the smaller molds.

\section{FORGEABILITY}

A number of forging defects have been encountered in high energy rate forged (HERF) JBK-75 parts. Defects such as adiabatic shear bands, cracks associated with shear bands, feathering, and nonuniformities in microstructure on a macroscopic scale (i.e., areas of dynamically recrystallized grains in a warm-worked part) have been observed. To date, these defects have been considered to be a function of processing parameters such as die design, rate and amount of reduction given the part in each die stage and lubrication. However, initial results of two different forgeability tests indicate that microstructure also plays an important role in the ability of JBK-75 to deform hom ogeneously. Homogeneous deformation precludes flow localization and, therefore, the above mentioned forging defects. Forgeability tests show that flow localization appears to be more acute when eta phase is present.

The following discussion will briefly describe the various forging defects, the results of the two forgeability tests, and finally, the relationship between forgeability and homogeneity.

Adiabatic shear bands form when macroscopic plastic flow is concentrated in a very localized volume of material. Inhomogeneous shear results in a narrow band as shown in Figure 5. Generally, these bands are orientated approximately $45^{\circ}$ to the maximum reduction direction (on planes of maximum shear stress) as shown in Figure 6. Cracks are often found to nucleate and grow along the shear bands (see Figure 7). In general, shear band formation in JBK-75 has occurred in the $870-900{ }^{\circ} \mathrm{C}$ forging temperature range.

Shear bands have also been found to occur in $\mathrm{Al}$, $\mathrm{Ti}, \mathrm{Fe}$, and $\mathrm{Cu}$ metals and base alloys, ${ }^{1}$ during cold rolling ${ }^{2,3}$ as well as cold explosive or impact forming. ${ }^{4}$ Adiabatic shear band formation in
HSLA steel is promoted at low temperatures (room temperature) and high strain rates $\left(400 \mathrm{sec}^{-1}\right) .^{5}$ In general, it has been shown that deformation instability is reached more quickly in metals that deform via planar dislocation motion (vs. cross slip) where work, on the finest scale, occurs in an inhomogeneous manner. This effect is accentuated; that is, planar slip is favored at high strain rates characteristic of HERF. ${ }^{6}$ Furthermore, Servillano, et al., ${ }^{2}$ cite a relationship between the propensity for shear band formation and stacking fault energy (SFE); that is, materials with low SFE will be more susceptible. For example, stainless steels (low SFE $\sim 200 \mathrm{ergs} / \mathrm{cm}^{2}$ ) will have a higher propensity for shear band formation than aluminum and copper (high SFE:Al $\sim 200 \mathrm{ergs} / \mathrm{cm}^{2}$ ). Note that metals with a low SFE tend to deform by planar slip, and also that SFE and deformation mode can be affected by temperature, microstructure, and chemistry. ${ }^{7}$ Therefore local variations in chemistry in JBK-75 and related second-phase precipitation at the forging temperature may have a profound effect on deformation mode and thus shear band formation.

Violan ${ }^{8}$ showed in Armco iron that larger grain sizes shift the deformation instability range to lower temperatures and higher strain rates. In other words, the larger-grained structures promoted stable or homogeneous deformation and were, therefore, less susceptible to shear band formation.

Backman and Finnegan ${ }^{4}$ related the initiation of adiabatic shear band cracks to surface stress risers (flaws, pits, scratches) as well as internal inhomogeneities. In JBK-75, microstructural inhomogeneities during forging may include local concentrations of Ti $(C, N)$, cellular $M_{23}(C, N)_{6}$, cellular and/or Widmanstatten eta, and duplexed grain size banding. Except for $\mathrm{M}_{23}(\mathrm{C}, \mathrm{N})_{6}$ precipitates, the above conditions can be related to the titanium segregation present in the starting stock. Investigations ${ }^{9,10}$ have shown that hot workability in superalloys is degraded by high concentrations of carbides, sulfides, and segregation-prone elements. Thus, well homogenized stock should be less apt to form local inhomogeneities and be less susceptible to shear band initiation. 


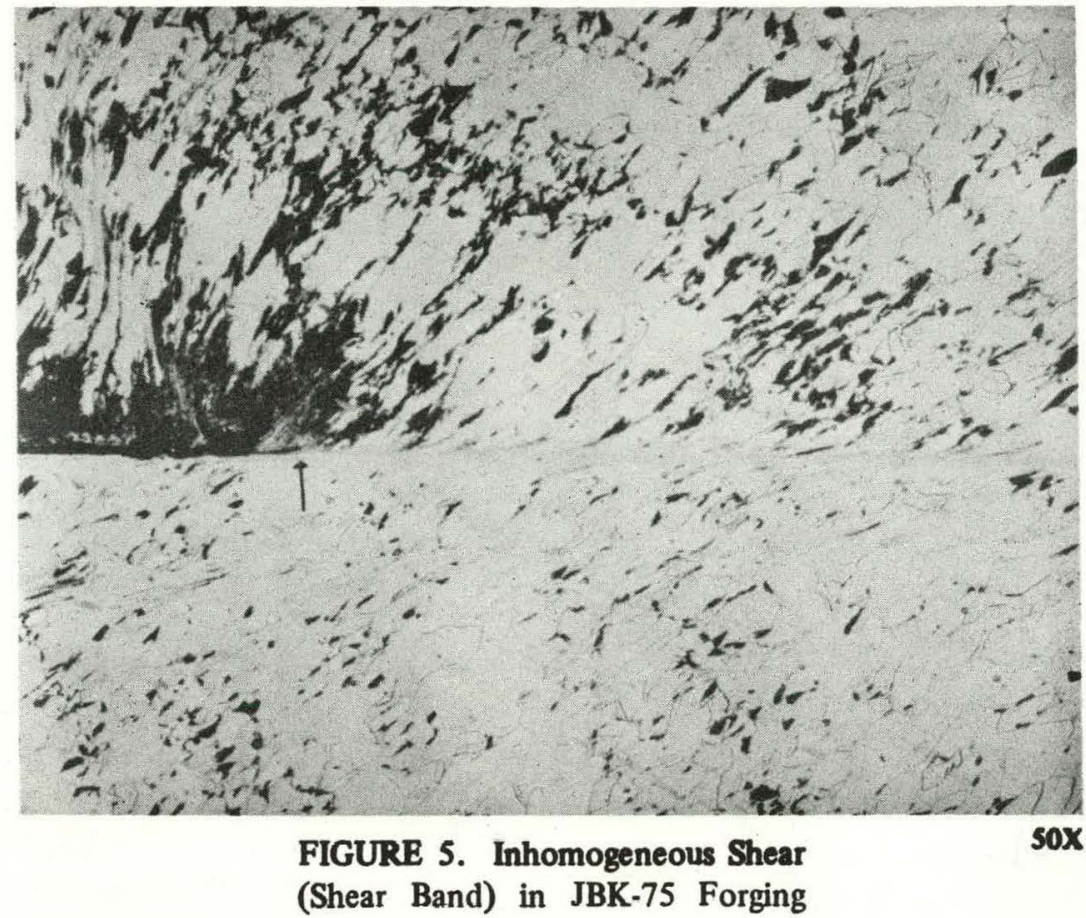

FIGURE 6. Shear Band in an SP944 JBK-75 HERFED Forging Orientated at $45^{\circ}$ in the Plane of Maximum Shear Stress. Forging was done at $880^{\circ} \mathrm{C}$.

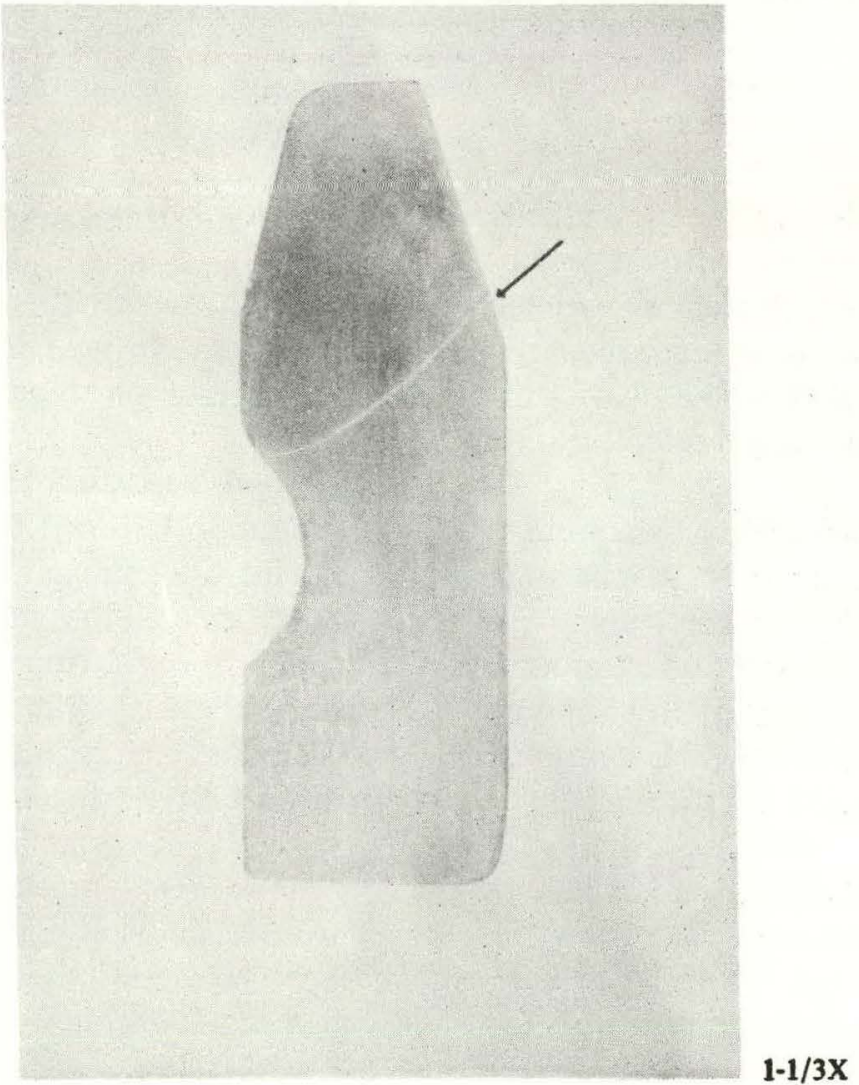




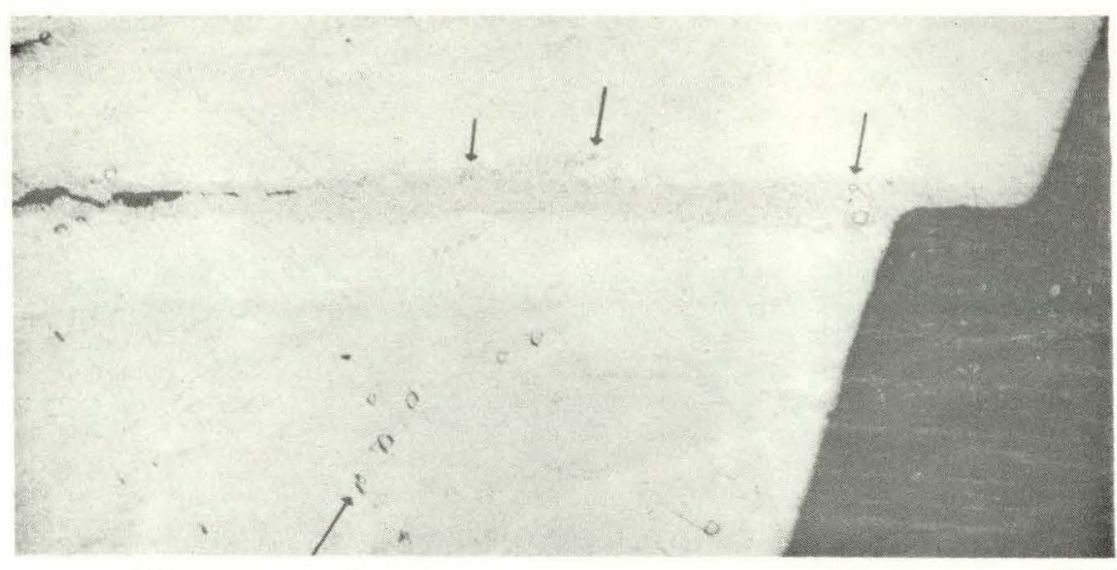

FIGURE 7. Macroscopic Offset in JBK-75 Forging Due to 150X Adiabatic Shear. Crack at left propagated within the band.

Cracks occur in the bands when recovery processes cannot support the high degree of localized strain. Higher forging temperatures should increase local strain before rupturing occurs because recovery processess will be more rapid. ${ }^{4}$

"Feathering" type defects are thought to be widened shear bands. Here, the combination of processing and material parameters are such that deformation is distributed in a more homogeneous manner relative to the case for shear band formation.

Lastly, adjacent areas of dynamic recrystallization and warm worked structure can be most readily eliminated by changes in the processing variables. However, forgeability tests show that material condition does have an effect on the distribution of work and thus on the as-forged microstructure.

Two different types of forgeability tests were conducted to determine rupture resistance and flow characteristics of JBK-75. The tests consisted of upsetting a side notched cylinder and a dumb-bell shaped specimen at room temperature, $650{ }^{\circ} \mathrm{C}, 870{ }^{\circ} \mathrm{C}, 980^{\circ} \mathrm{C}$, and $1093^{\circ} \mathrm{C}$. Upsetting was done between flat dies at high strain rate $\left(\sim 1000 \mathrm{sec}^{-1}\right)$ on a Dynapak HERF machine. The test specimens are shown in Figure 8. A stop ring was used to ensure uniform reduction from specimen to specimen. Prior to upsetting, the samples were heated, with an attached thermocouple, for $1 / 2$ hour at temperature.
The results of the upset rupture test are shown in Figure 9. The greatest susceptibility to rupture occurred at $870{ }^{\circ} \mathrm{C}$, in the eta precipitation range. Metallographic analysis showed that eta was more prevalent in this specimen. See Figure 10. Further analysis showed the presence of shear bands leading the crack tips as shown in Figure 11. Assuming that the bands formed prior to rupturing (the classic case), it appears that the presence of eta leads to early deformation instability and shear band formation and subsequently, to a higher degree of rupturing.

It is interesting to note that Kane ${ }^{11}$ found a similar trough in hot workability at $870^{\circ} \mathrm{C}$ in Type 310 stainless steel. Degradation in workability was related to nitrogen content and possibly to the presence of a nitrogen precipitate (i.e., $\mathrm{Cr}_{2} \mathrm{~N}$ ).

Similarly, elevated temperature ductility loss has been reported for Discalloy, A-286, 316, and 304. ${ }^{12}$ Further, hot impact tensile tests of V-57 showed that a gradual loss in ductility will occur as temperature is lowered from 1093 to $980^{\circ} \mathrm{C}$. Rapid loss begins between 925 and $980{ }^{\circ} \mathrm{C}$ and ends near $760{ }^{\circ} \mathrm{C} .{ }^{13}$ In the nickel base superalloy, Rene 41 , forgeability is degraded by the presence of carbides [i.e., $\mathrm{M}_{23}(\mathrm{CN})_{6}$ and $\mathrm{M}_{6} \mathrm{C}$ ] as well as $\gamma$, which is $\mathrm{Ni}_{3}(\mathrm{Al}, \mathrm{Ti}) \cdot{ }^{14}$ In this case the minimum in the trough occurs at higher temperatures, near $980^{\circ} \mathrm{C}$, because the respective precipitation ranges are higher. Many superalloys show similar ductility losses at intermediate temperatures. ${ }^{15}$ 


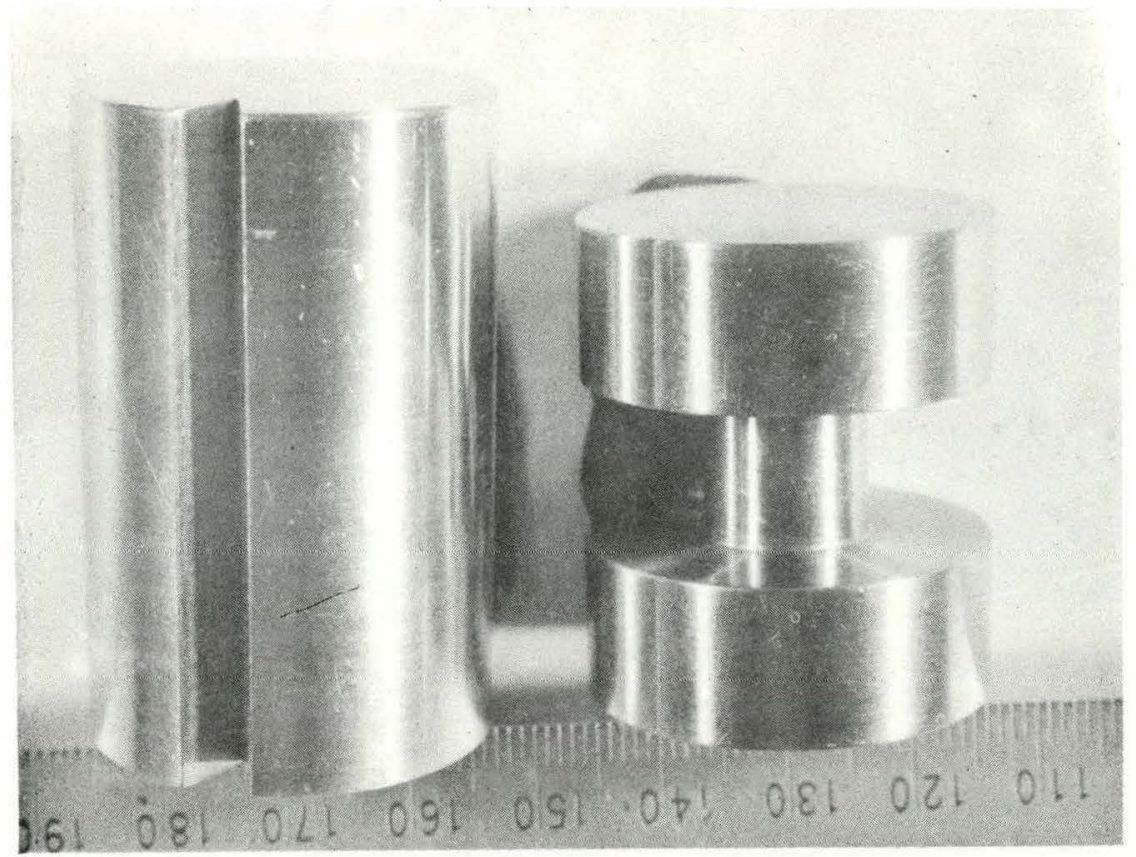

FIGURE 8. Forgeability Test Specimens. Notched cylinder (left) and dumb-bell specimen (right).

FIGURE 9. HERF Notched Cylinders. Forging temperatures were from top to bottom: Room temperature and $650^{\circ} \mathrm{C}, 870^{\circ} \mathrm{C}, 980^{\circ} \mathrm{C}$, and $1093^{\circ} \mathrm{C}$.

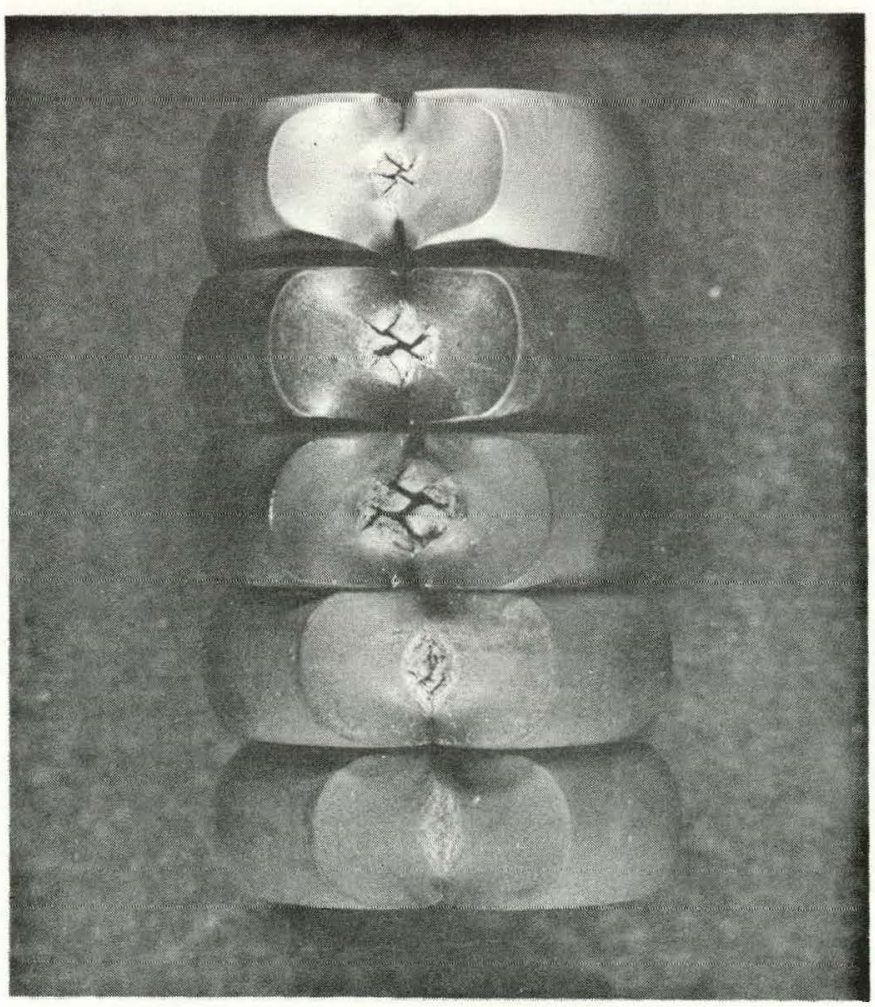


RFP-2925

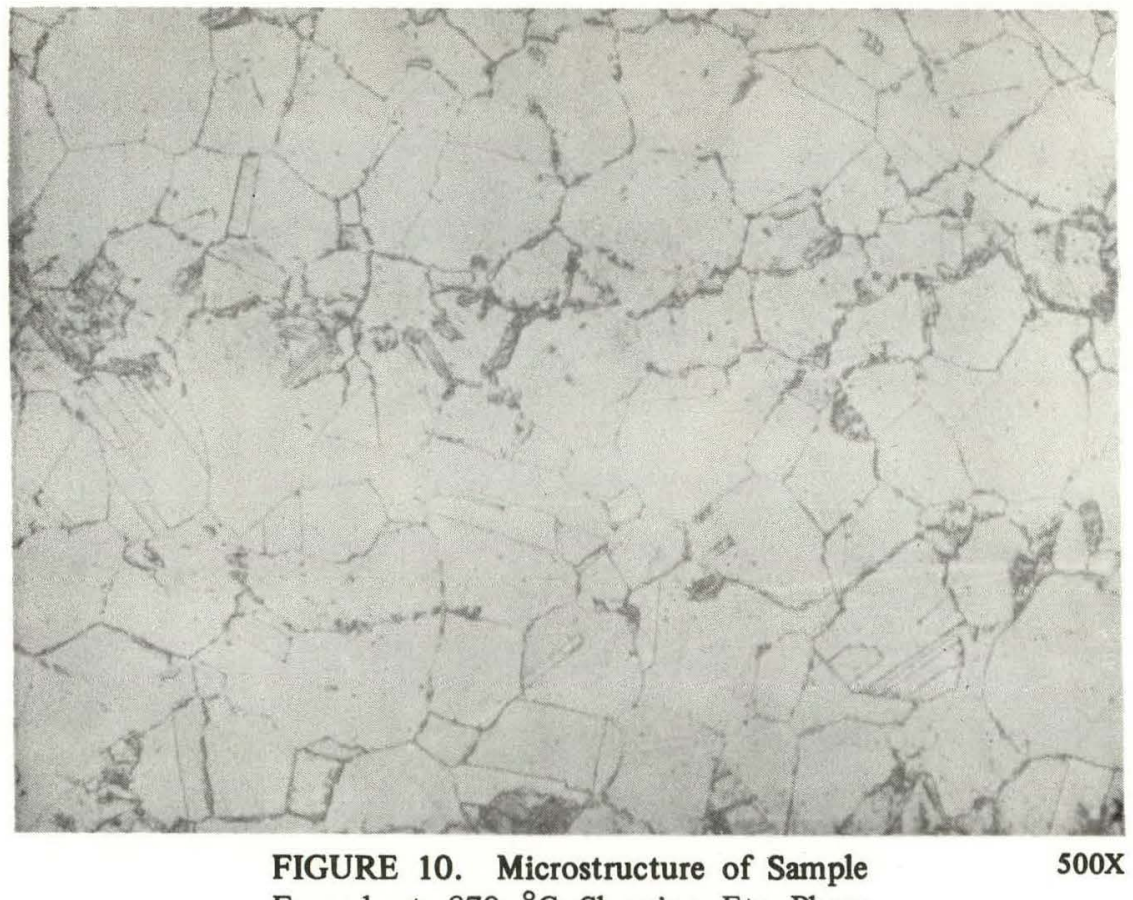

Forged at $870{ }^{\circ} \mathrm{C}$ Showing Eta Phase

FIGURE 11. Shear Band Leading a Crack in a JBK-

75 HERF Notched Cylinder Forgeability Speci-

men. Upsetting was done at room temperature.

$50 \mathrm{X}$

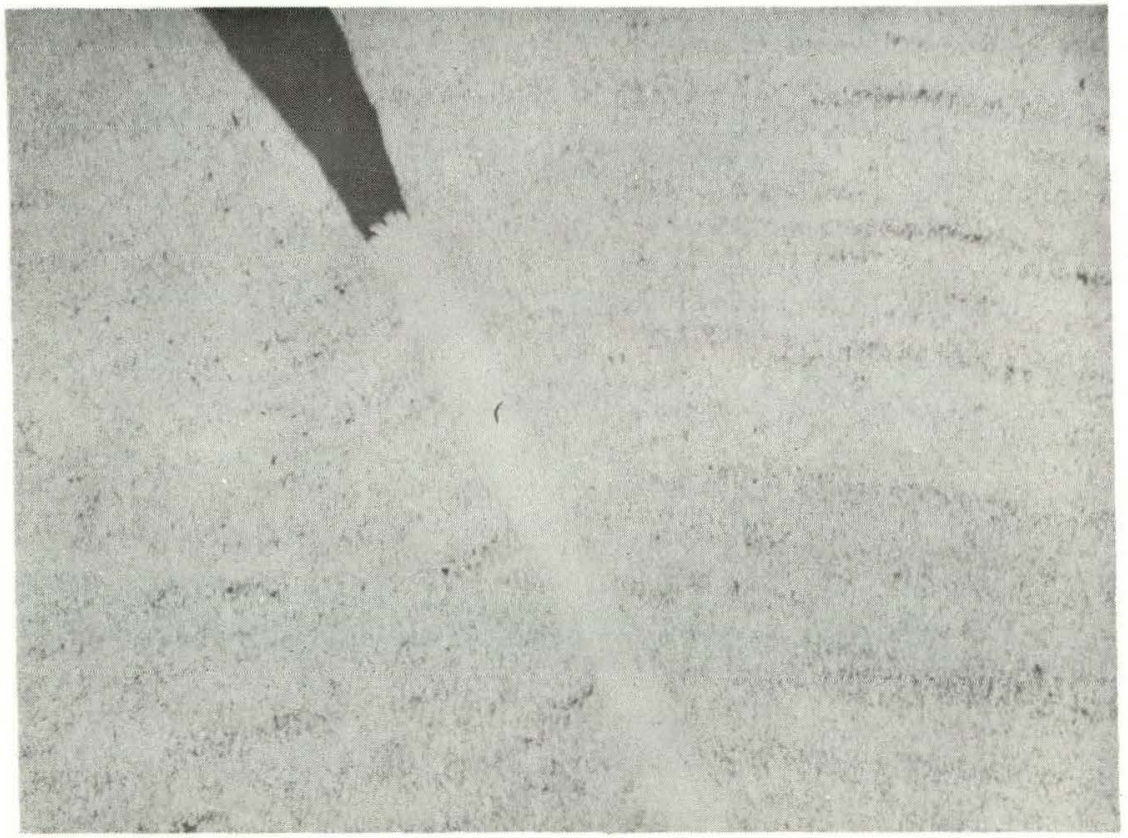




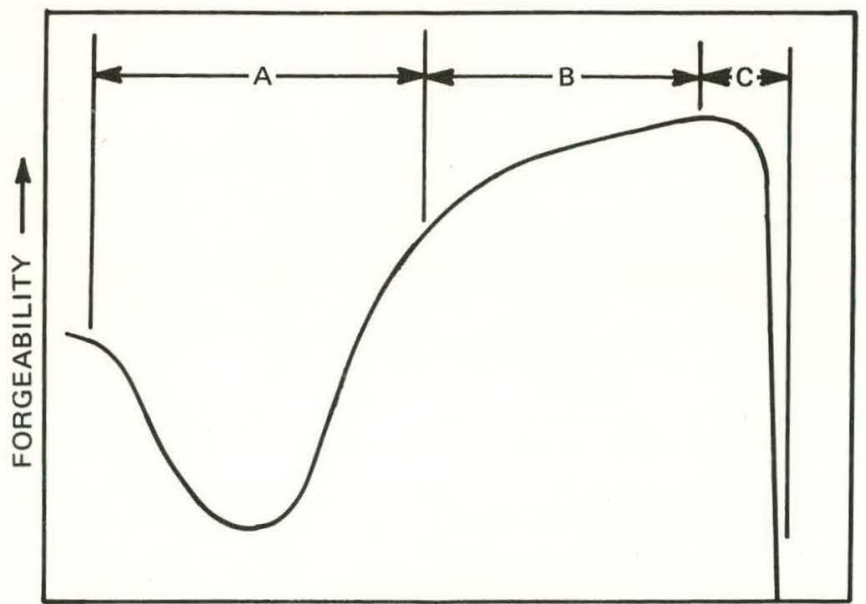

FORGING TEMPERATURE

FIGURE 12. Schematic of Forgeability Versus Forging Temperature for JBK-75 and Similar Alloys. Forgeability is shown to be primarily a function of precipitate structure (eta in JBK-75) in Region A, recovery and recrystallization in $\mathrm{B}$, and incipient melting in $\mathrm{C}$.

Yeniscavich ${ }^{16}$ suggests that the ductility loss at these intermediate temperatures is due in part to the retardation of dynamic recrystallization during working and to overall matrix hardening by the precipitate. It is suggested here that second phase particles can also impede grain boundary motion, and llus retard recrystallization. A scliematic showing the dependence of forgeability on second phase precipitation is shown in Figure 12. Forgeability is generally improved in single-phase regions.

Summarizing the results of the notched cylinder upset test, it can be said that eta decreases rupture resistance apparently by increasing deformation instability. Shear bands appear to be the precursor to rupturing. Control of shear bands, like flow lines, is critical to the application.

The results of the dumb-bell upset test were interpreted from forged specimen dimensional analysis, Table 2, and from polished and etched cross sections shown in Figure 13. From the table, one can see that the work given to the sample is apportioned between the gate section and specimen ends. The work results in increased diameters in both locations. The ability to distribute the deformation was curtailed at the $870{ }^{\circ} \mathrm{C}$ test, presumably due to the presence of eta. As shown in Table 2, only $1 \%$ (approx.) of the original gage volume was distributed to the specimen ends while $18 \%$ or greater was distributed at all other forging temperatures. Deformation was, therefore, more homogeneous throughout the specimen at forging temperatures other than $870{ }^{\circ} \mathrm{C}$ where eta did not form. At these temperatures, the gage section effectively strain hardened to the point that the specimen ends were deformed substantially. However, at $870{ }^{\circ} \mathrm{C}$, it appears that this degree of strain hardening did not occur but rather a loss of strain hardening capacity or strain softening was induced by the eta. Therefore, the specimen ends deformed less because deformation could be concentrated in the relatively soft gage area.

This condition is further highlighted by the local grain flow transition and fold angle between the specimen ends and bulged gage section. See Figure 14. In the $870^{\circ} \mathrm{C}$ specimen, the grain flow shows a high degree of instability or sharp directional changes which appear to be leading the formation of a shear band. Also, the fold is at right angles to the specimen axis. This shows that the gage section bulged to a greater degree because the deformation was not effectively transmitted to the specimen ends but instead was localized in the gage section.

Summarizing these results, it is shown that the presence of eta causes flow localization during deformation. Flow localization is a prerequisite for the formation of forging defects. The degree of localization determines the type of defects formed. The precise mechanism by which flow localization occurs has not been established in this study, but it has been shown that eta phase induces it.

Flow localization can be described as a self sustaining or autocatalytic reaction. For example, at the instant that deformation becomes localized as a result of stress state or material inhomogeneity, that portion of material (deforming to a greater degree) may soften (relative to the rest of the material) either from work softening, thermal softening from adiabatic heating, or dynamic recrystallization and/or recovery. Further deformation will then be concentrated in this "soft" region and a defect such as a shear band is created. 
RFP-2925

TABLE 2. Measurements of Forged Dumb-Bell Specimens and Calculated Volume Change in the Gage Section

Forging

Temperature

$\left({ }^{\circ} \mathrm{C}\right)$

Room

$650^{\circ} \mathrm{C}$

$870^{\circ} \mathrm{C}$

$980^{\circ} \mathrm{C} \quad 1093^{\circ} \mathrm{C}$

Measurement

$(\mathrm{cm})$

A

B

1.582

0.592

$\begin{array}{ll}1.709 & 1.991\end{array}$

$0.536 \quad 0.512$

1.836

0.498

1.796

C

$\begin{array}{lll}3.116 & 3.058 & 3.040\end{array}$

$3.015 \quad 2.997$

D

3.216

$3.210 \quad 3.185$

$3.218 \quad 3.238$

(\%) $\Delta \mathrm{V}$ gage*

27.6

23.5

1.0

$18.0 \quad 38.0$

*This value is the percentage of the original gage volume that was distributed to the specimen ends during forging. Lower values represent deformation instability and flow localization.

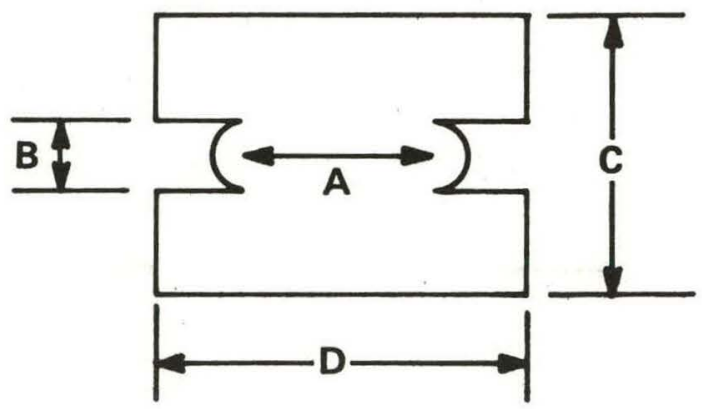

$$
\begin{aligned}
& \mathrm{Vi}=1.608 \mathrm{~cm}^{3} \\
& \mathrm{Vf} \cong(\mathrm{B})\left(\frac{\Delta}{2}, \pi\right) \\
& \%\left(\frac{\Delta \mathrm{V}}{\mathrm{Vi}}\right)=\frac{\mathrm{Vi}-\mathrm{Vf}}{\mathrm{Vi}} \times 100
\end{aligned}
$$




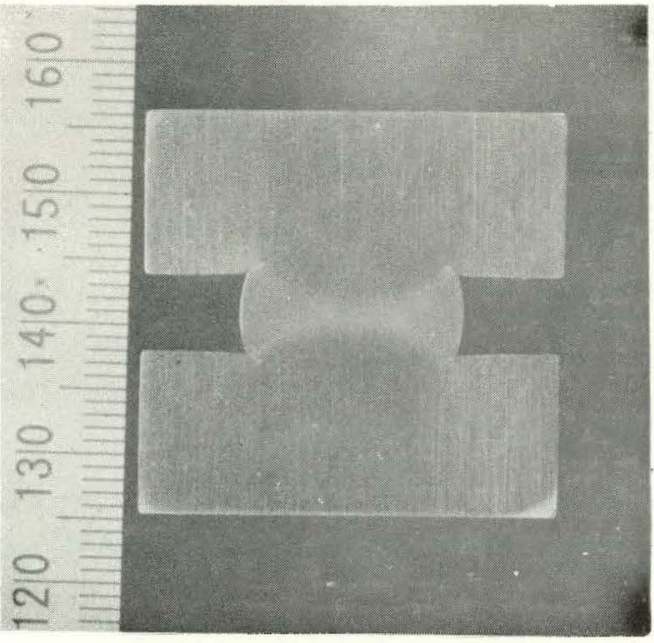

Room Temperature

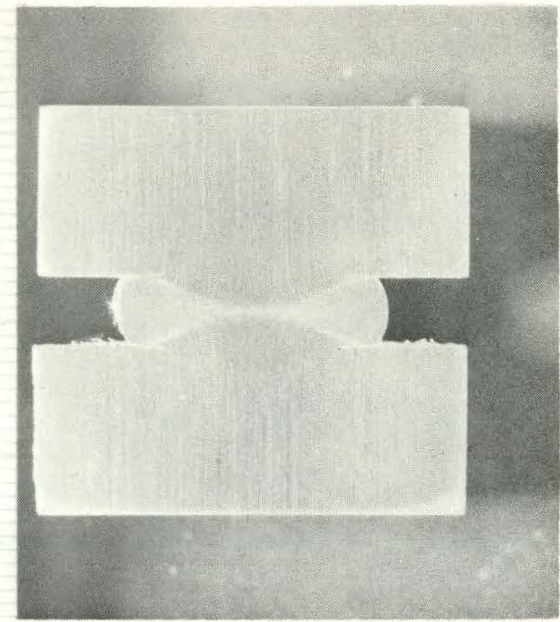

$650^{\circ} \mathrm{C}$

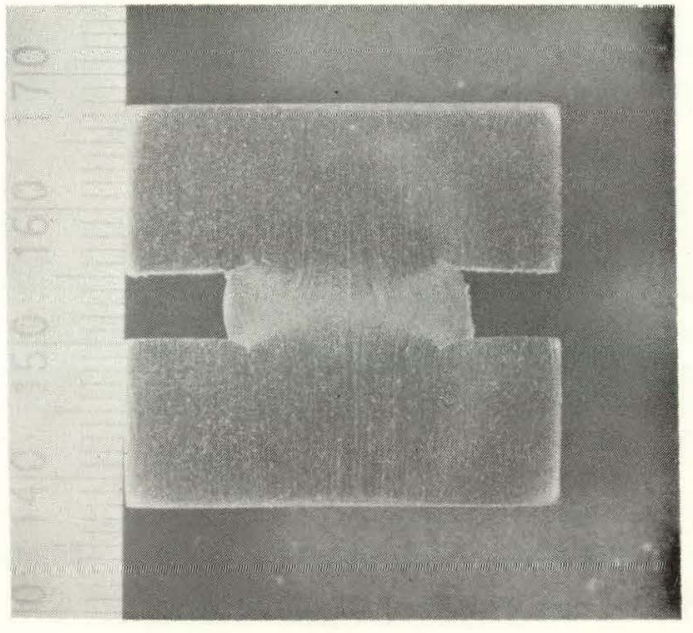

$870^{\circ} \mathrm{C}$

$980^{\circ} \mathrm{C}$

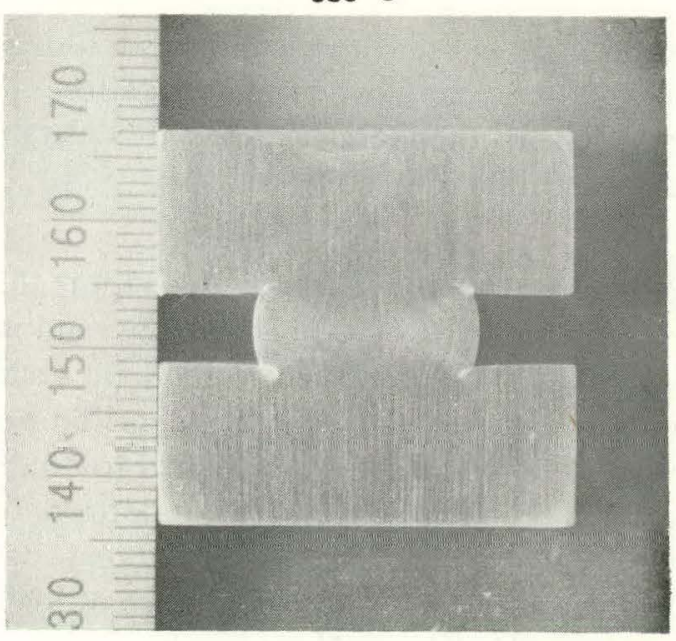

FIGURE 13. Cross-Sectioned and Macroetched Dumb-Bell Forgeability Upsets $1093^{\circ} \mathrm{C}$

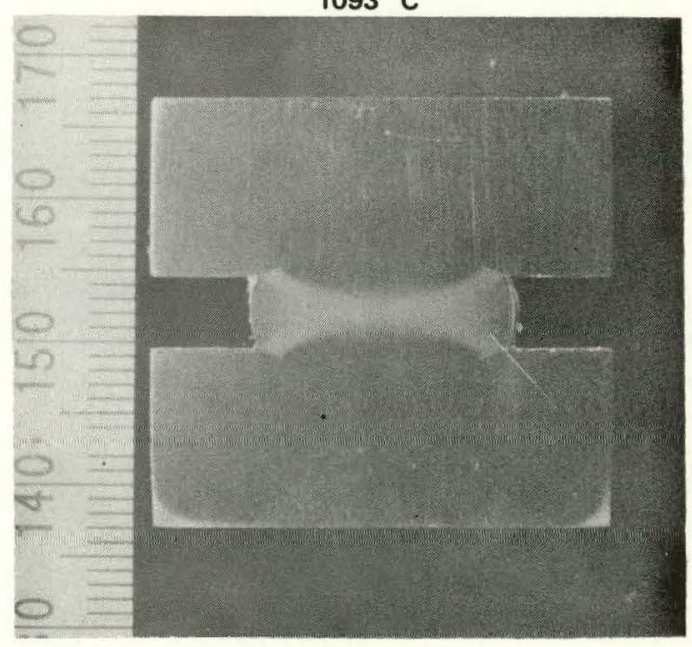


RFP-2925

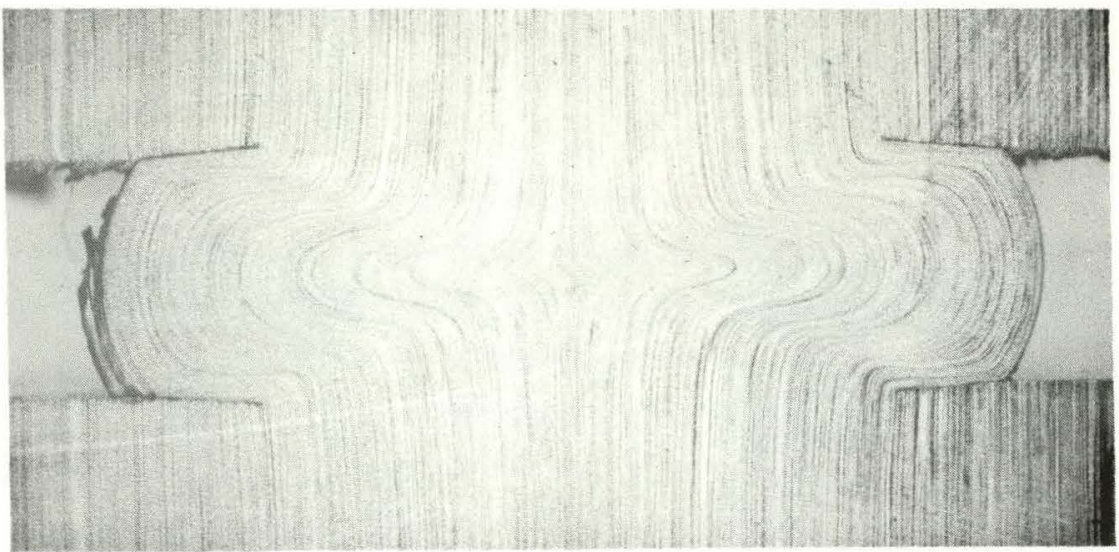

$870^{\circ} \mathrm{C}$

$980^{\circ} \mathrm{C}$

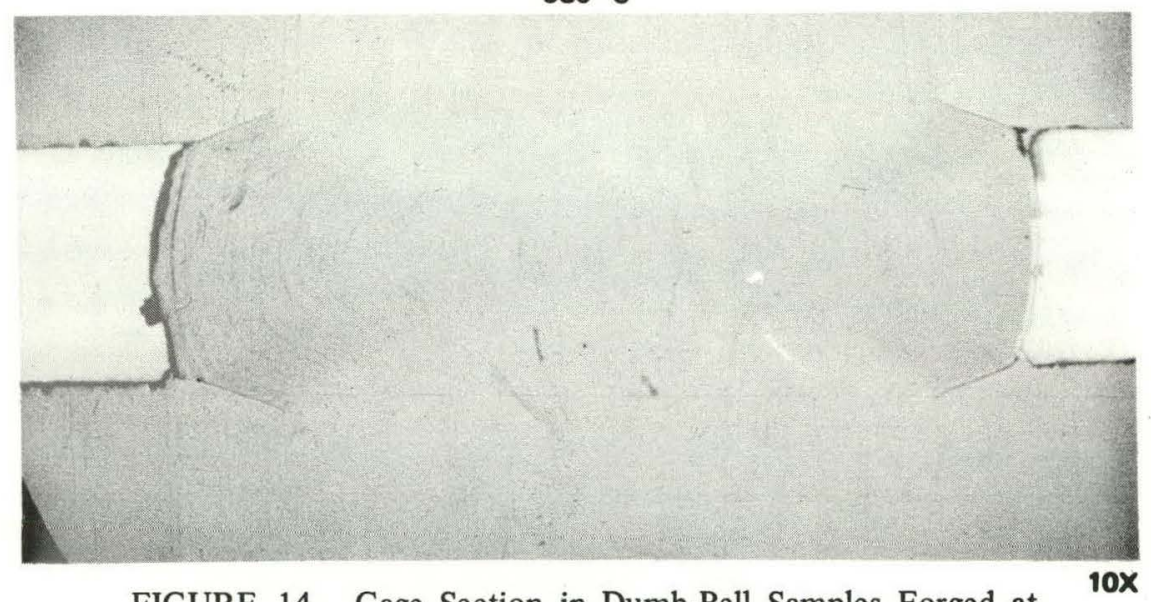

FIGURE 14. Gage Section in Dumb-Bell Samples Forged at $870{ }^{\circ} \mathrm{C}$ and $980{ }^{\circ} \mathrm{C}$ Showing the Angle of the Fold Between the Gage Section (Center) and Specimen Ends and Grain Flow

Since eta phase is known to be detrimental to hot workability, it should be avoided. High titanium in JBK-75 is known to increase the temperature of eta solvus. ${ }^{16}$ Extremely segregated JBK-75 is more prone to form eta phase at the lower end of the temperature range. However, inhomogeneous material of $2.1 \% \mathrm{Ti}$, the eta solvus temperature is $890^{\circ} \mathrm{C}$, or about $60{ }^{\circ} \mathrm{C}$ below the lower end of the forging temperature range. Figures 15 and 16 illustrate the effects of homogeneity on forgeability.

As shown in Figure 16, the degree of segregation, $\mathrm{S}$, can dramatically restrict the forging temperature range.
It has been shown that forgeability is a function of carbide, sulfide, and elemental segregation. Random distributions of these constituents are desirable for good forgeability.

It has been shown elsewhere in this report that the more hom ogeneous JBK-75, the more random are the distributions of carbonitride and eta precipitates. Thus, forgeability will be increased as homogeniety increases. Tests are being conducted to confirm these findings. The propensity for deformation instability or flow localization and thus for a greater forging defect probability is increased at higher strain rates (i.e., in HERF). Since much of our product 
RFP-2925

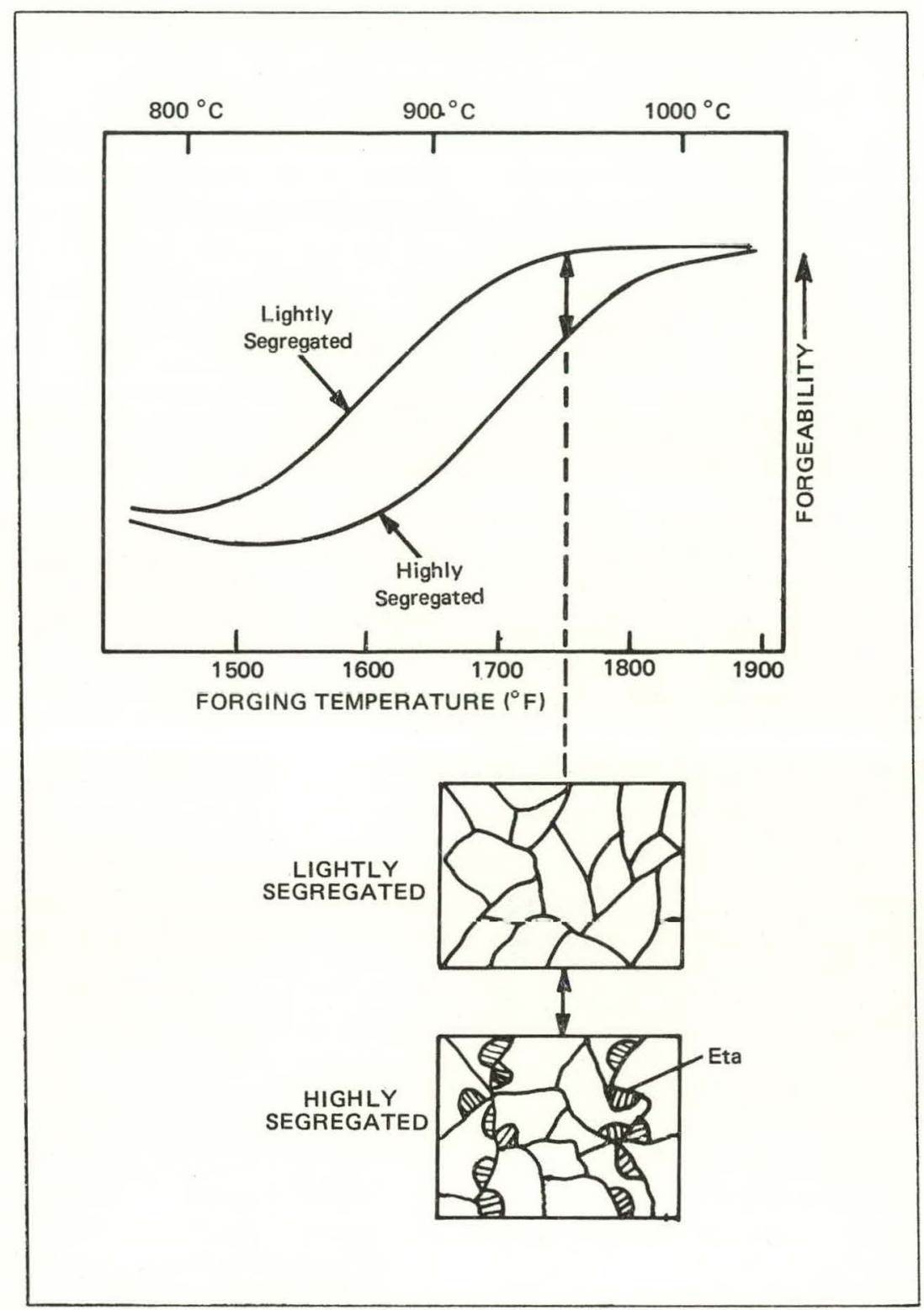

FIGURE 15. Schematic Showing Loss of Forgeability for JBK-75 at $953{ }^{\circ} \mathrm{C}$ Due to Eta Precipitation in High Titanium Bands. The optimum forging temperature range is effectively reduced in highly segregated material. 


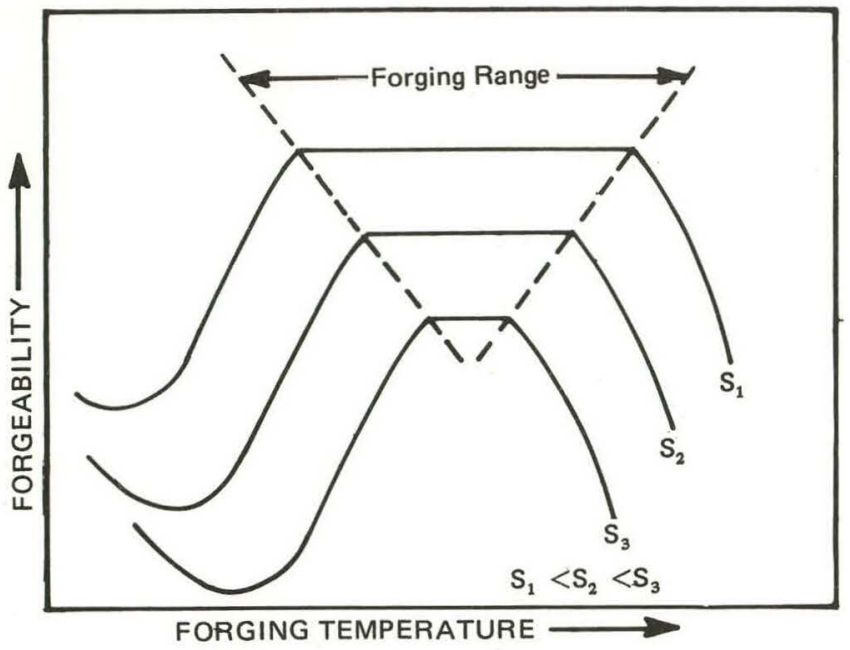

FIGURE 16. Schematic of Forgeability Versus Forging Temperature Showing a Reduction in Forging Temperature Range for Greater Degrees of Segregation (S)

is produced by HERF and forging defects have been observed in this product, it is necessary to try to control the starting material condition as well as the processing parameters to minimize the probability of forging defects. This can be done by minimizing Ti segregation in the stock. Methods to improve homogenization are discussed elsewhere in this report.

\section{REDUCTION OF TITANIUM SEGREGATION THROUGH HOMOGENIZATION}

Titanium segregation in JBK-75 bar stock may result in a number of microstructural inhomogeneities in forged parts; accentuated flow lines, bands of duplexed grain sizes, $\mathrm{TiC}$ and $\mathrm{Ti}(\mathrm{C}, \mathrm{N})$ stringers, local variations in volume percent of $\gamma^{\prime}$ aging precipitate, and bands of eta $(\eta)$ phase, see Figures 17-21, respectively. Macroscopic tests, such as the tensile test used for JBK-75 forging quality assurance, do not appear to be very sensitive to these microscopic variations. However, it is generally recognized that many macroscopic physical and mechanical properties can be a function of micro-local variations in chemistry and structure. Some of these are impact strength, notched tensile strength, microhardness, corrosion resistance, stress corrosion cracking resistance, resistance to hydrogen damage, fatigue crack initiation and propagation, forgeability at high temperatures, and weldability. It is generally agreed that improved homogeneity will result in improved part performance. It is on this basis that methods are being sought to reduce the Ti segregation in JBK-75. This section will treat improvements attainable through better homogenization treatments.

A model for Ti diffusion has been developed to review the effects of homogenization treatment on Ti distribution. The initial Ti concentration profile has been assumed to vary sinusoidally in one dimension and is then approximated by:

$$
\mathrm{C}(\mathrm{X}, \mathrm{O})=\mathrm{C}_{\mathrm{m}}+\mathrm{C}_{\mathrm{A}} \operatorname{Cos} \frac{\pi \mathrm{x}}{\mathrm{L}}
$$

where $\mathrm{C}(\mathrm{X}, \mathrm{O})$ is the concentration of $\mathrm{Ti}$ at position $\mathrm{x}$ and time $=\mathrm{O} ; \mathrm{C}_{\mathrm{m}}$, the mean composition; $\mathrm{C}_{\mathrm{A}}$, the amplitude of variation at time $=\mathrm{O}$; and $\mathrm{L}$, the half wavelength. See Figure 22.

To determine the effects of homogenization on the Ti profile, a solution to Fick's Second Law must be found. Fick's Second Law is:

$$
\frac{\partial C}{\partial t}=\frac{\partial}{\partial x}\left(D \frac{\partial C}{\partial x}\right)
$$

where $\mathrm{t}$ is the time; $\mathrm{C}$, the concentration of $\mathrm{Ti}$; $\mathrm{D}$, the diffusion coefficient; and $x$, the distance. An accepted solution is:

$$
\begin{gathered}
\mathrm{C}(\mathrm{X}, \mathrm{t})=\mathrm{C}_{\mathrm{m}}+\mathrm{C}_{\mathrm{A}}\left(\operatorname{Cos} \frac{\pi \mathrm{X}}{\mathrm{L}}\right) \\
\left(\exp -\frac{\mathrm{Dt} \pi^{2}}{\mathrm{~L}^{2}}\right)
\end{gathered}
$$

where $\mathrm{C}(\mathrm{X}, \mathrm{t})$ is the $\mathrm{Ti}$ concentration at position $\mathrm{X}$ and time $\mathrm{t} ; \mathrm{C}_{\mathrm{m}}$ is $2.1 \% \mathrm{Ti} ; \mathrm{C}_{\mathrm{A}}$ is $\pm 0.6 \% \mathrm{Ti}$ (typical of Heats 96604, 06606, and 926). Time, t, has been varied from 0 to $8.6 \times 10^{5}$ seconds $(240 \mathrm{hr})$ and $\mathrm{L}$ from 300 microns $(\mu)$, in the 12.5 -cm diameter bar, to $960 \mu$, in the $40.6-\mathrm{cm}$ diameter ingot. $\mathrm{C}_{\mathrm{m}}, \mathrm{C}_{\mathrm{A}}$, and $\mathrm{L}$ have been quantitatively measured, via the microprobe, in $12.5-\mathrm{cm}$ diameter bar. Half wavelengths, L, for $20.3-\mathrm{cm}$ and $40.6-\mathrm{cm}$ diameter have been established from the $12.5-\mathrm{cm}$ bar, assuming a one-to-one correlation between diameter and band spacing. Therefore, the $\mathrm{L}$ values are calculated to be 480 and $960 \mu$, respectively. 


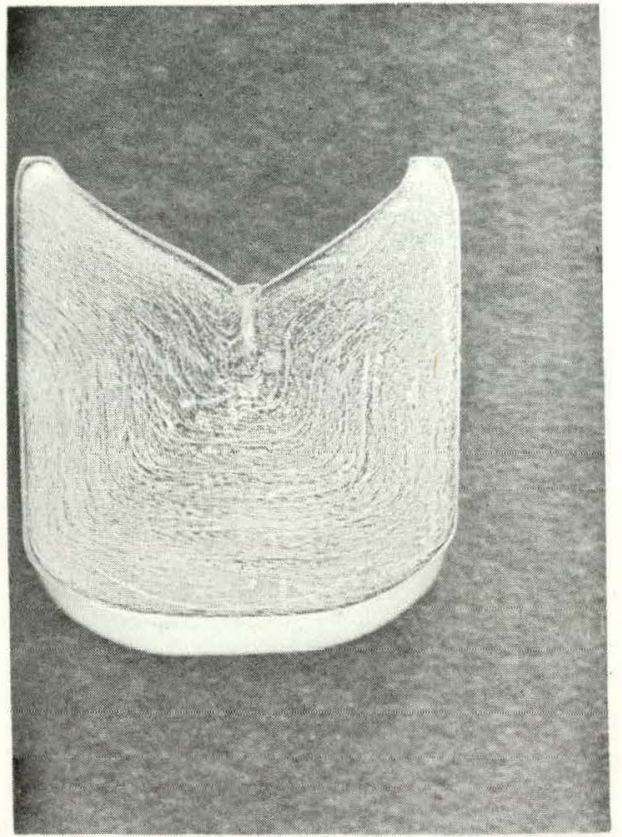

FIGURE 17. Accentuated Flow

Lines in a JBK-75 Press Forged Part

FIGURE 18. Grain Size Banding in JBK-75 Bar Stock

$100 x$

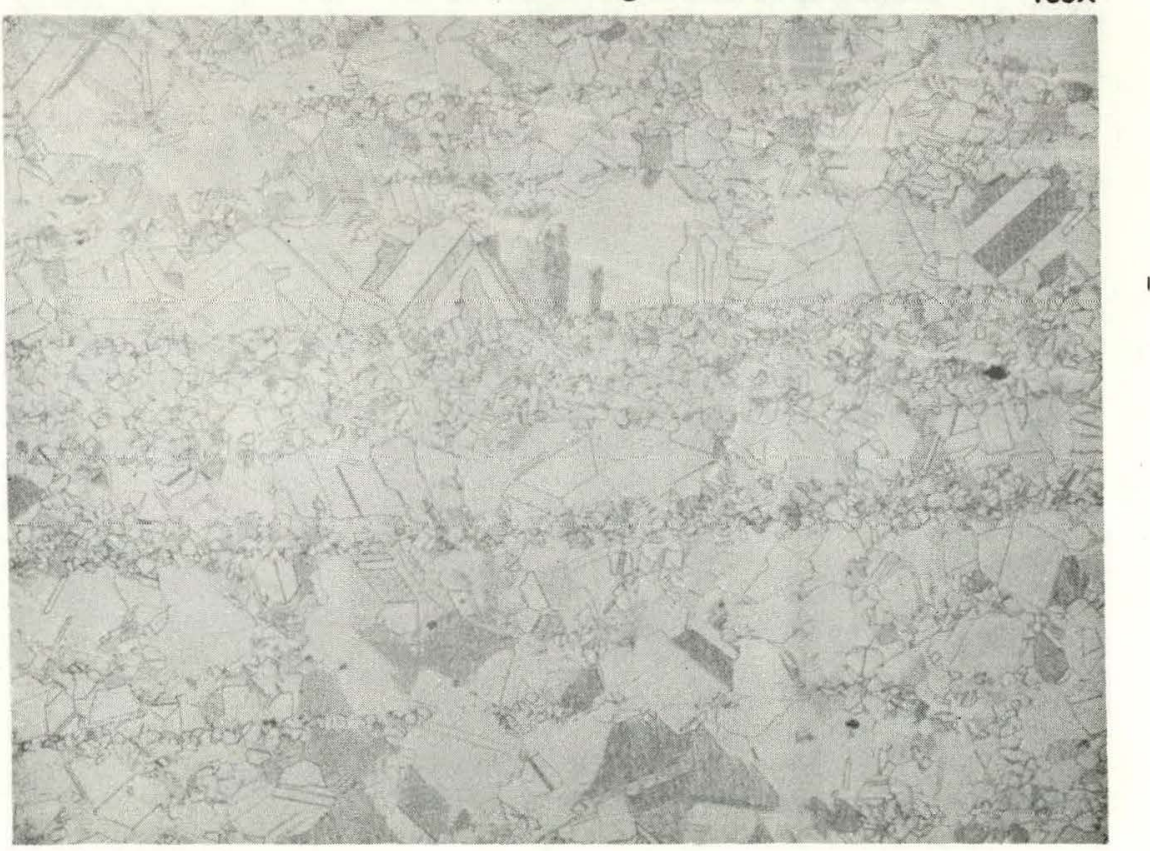


RFP-2925

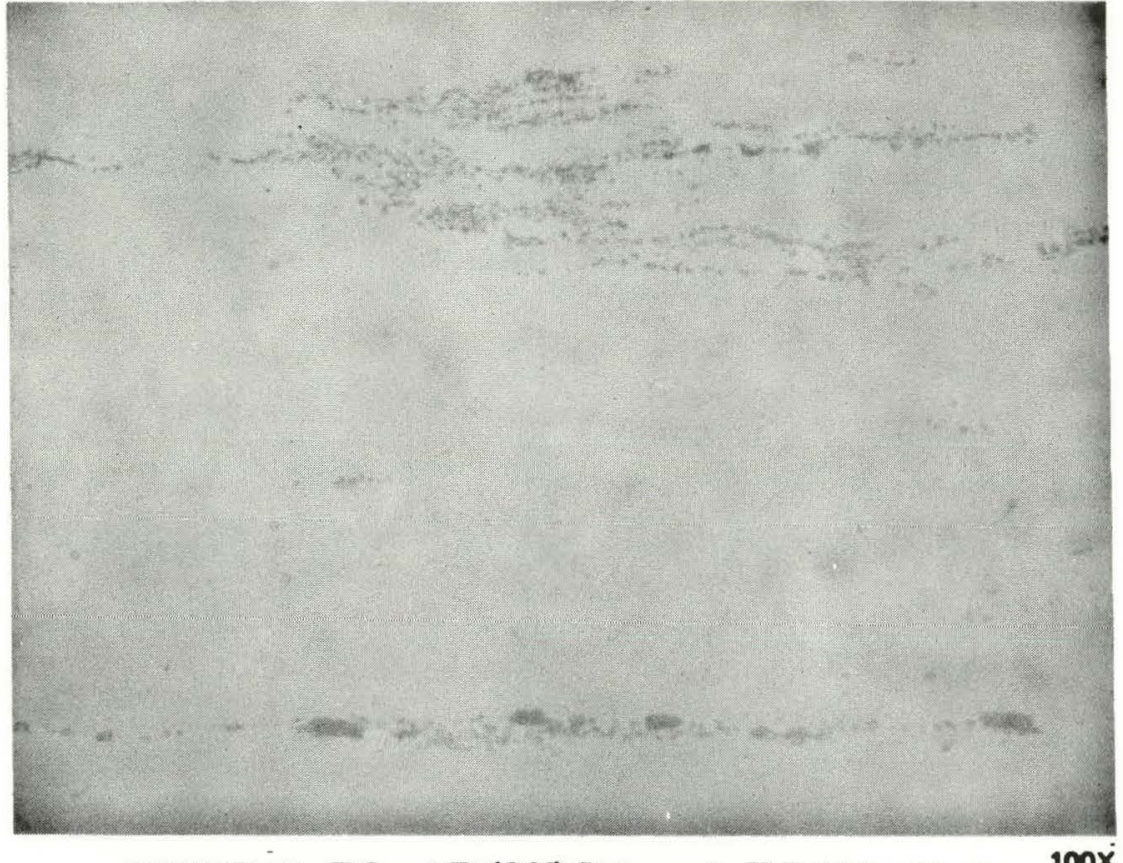

FIGURE 19. TiC and Ti (C,N) Stringers in JBK-75 Bar Stock

$100 x$

FIGURE 20, Local Variations in $\alpha^{\prime}$ Aging Precipitate in JBK.75 Bar Stock

$100 x$

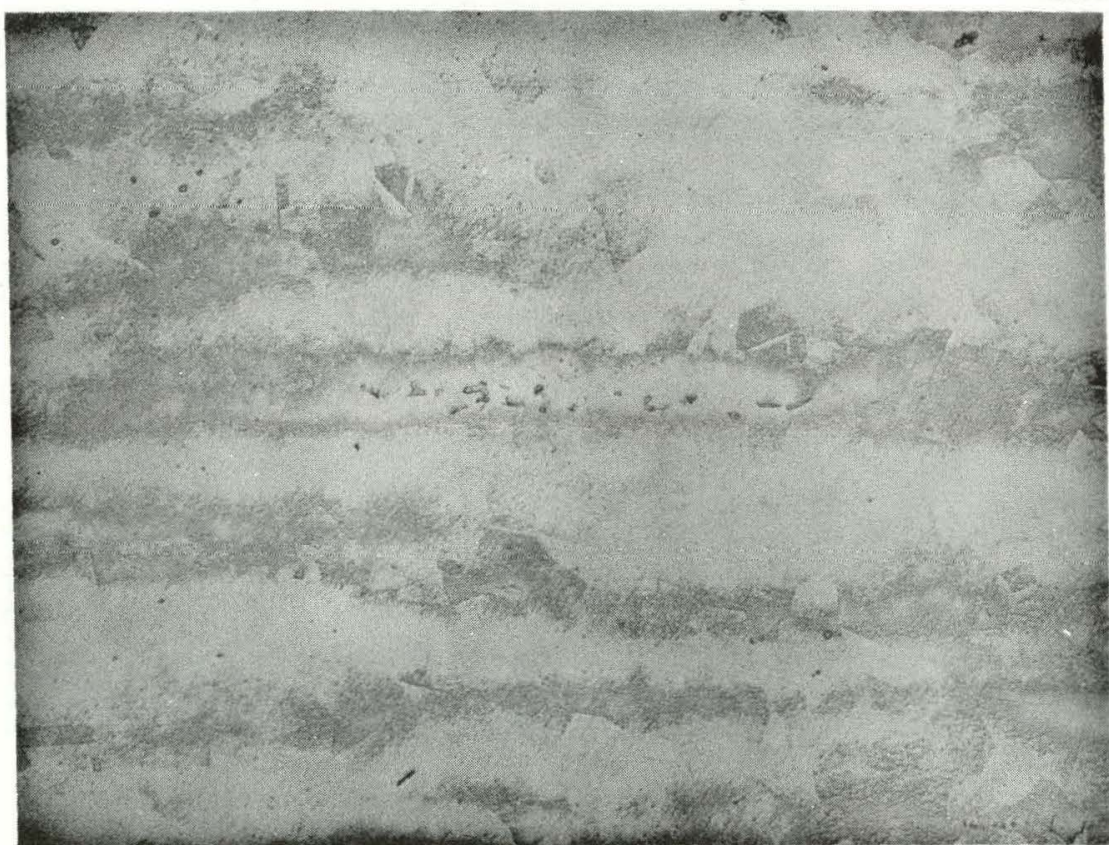




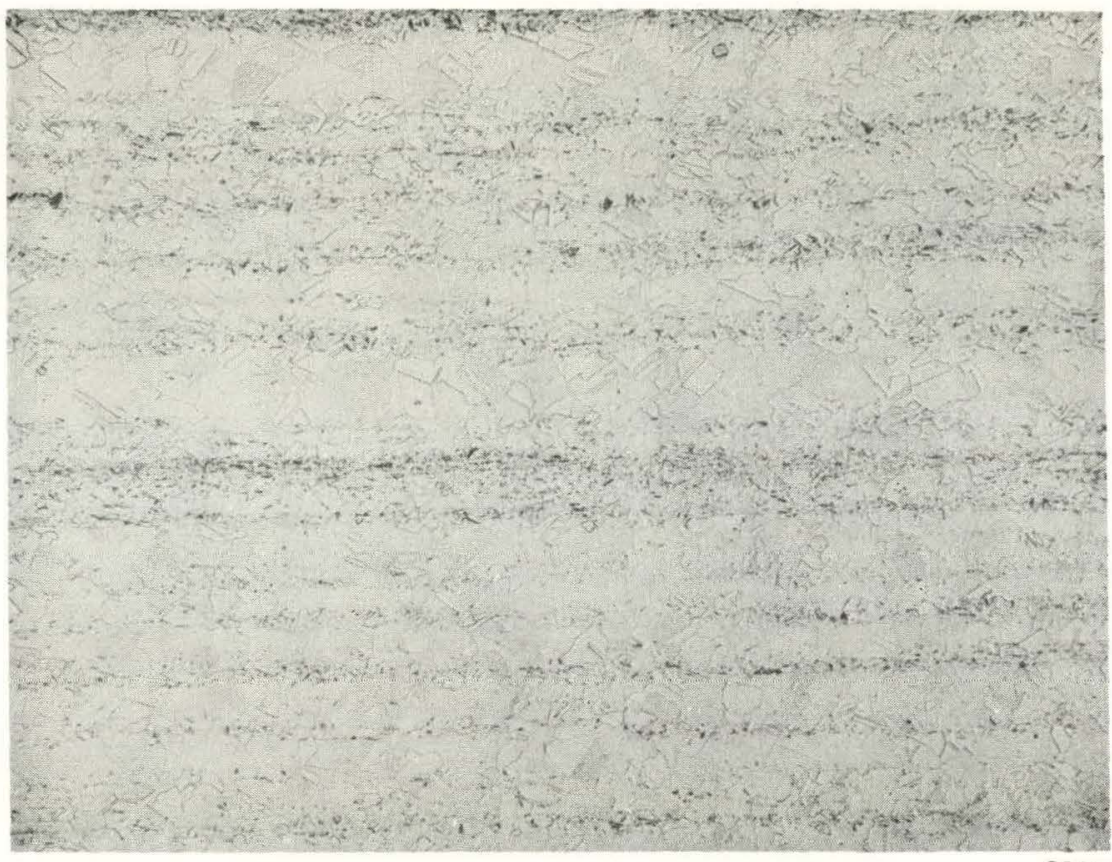

FIGURE 21. Bands With Large Amounts

$200 x$ of Eta $(\eta)$ Phase in JBK-75 Bar Stock

FIGURE 22. The Effect of Homogenizing Heat 926 for 164 Hours at $1180{ }^{\circ} \mathrm{C}$. Both experimental and theoretical results are shown.

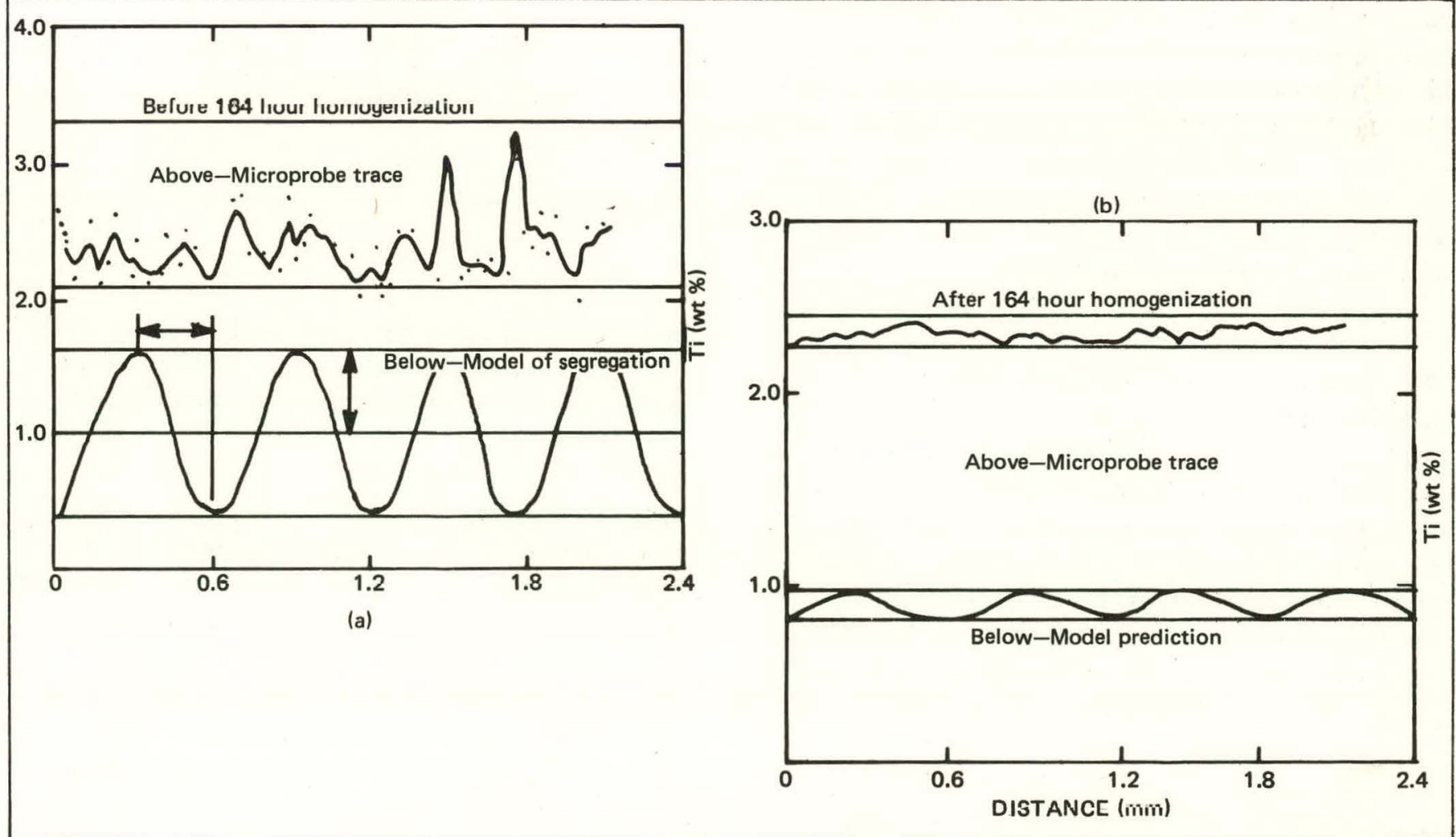


To solve equation ( 3 ), the diffusion coefficient, D for Ti in JBK-75 must be known. D can be found from:

$$
\mathrm{D}=\mathrm{D}_{\mathrm{O}} \exp ^{-\mathrm{Q} / \mathrm{kt}}
$$

where $\mathrm{D}_{\mathrm{O}}$ is the diffusion constant; $\mathrm{Q}$, the activation energy; $\mathrm{k}$, Boltzman's constant; and the $\mathrm{t}$, the homogenization temperature. Values for $\mathrm{k}$ and $\mathrm{t}$ are $1.38 \times 10^{-23} \mathrm{~J} /{ }^{\circ} \mathrm{K}$ and $1453^{\circ} \mathrm{K}$, respectively. Although diffusion data for Ti in JBK-75 does not appear to be available, two different sets of $\mathrm{D}_{\mathrm{O}}$ and $\mathrm{Q}$ are available for $\mathrm{Ti}$ in gamma iron. ${ }^{19}$ See Table 3. These values have been used in the following calculations. Substituting this data in equation (4) yields D values of $1.4 \times 10^{-10}$ and $2.43 \times 10^{-10} \mathrm{~cm}^{2} / \mathrm{sec}$ for $1180{ }^{\circ} \mathrm{C}$, the homogenization temperature. Using these results, equation (3) was solved for $\mathrm{C}(\mathrm{X}, \mathrm{t})$ as a function of the different band spacings corresponding to the different bar sizes. These results are tabulated in Table 4 and plotted in Figure 23. Also shown is the Ti segregation found in a number of vendor heats of $12.7-\mathrm{cm}$ diameter bar.

All heats shown, except the experimental heats, were vacuum arc melted into $40.6-\mathrm{cm}$ diameter ingots. The wide variation of Ti segregation from heat to heat cannot be explained by variations in homogenization treatment (current procedure - 16 to 24 hours at $1180^{\circ} \mathrm{C}$ ) since homogenization at the ingot stage is relatively ineffectual as shown in Figure 23. As discussed earlier the variations are thought to be generated during casting. Changes in melting practice to reduce Ti segregation are discussed elsewhere in this report.

The above model was checked experimentally by homogenizing Heat 926 which had approximately $\pm 0.6 \mathrm{Ti}$ concentration amplitude, $\mathrm{C}_{\mathrm{A}}$, and a $300 \mu$ half wavelength, $\mathrm{L}$, as shown in Figure 22. Samples were heat treated in Argon for $5.9 \times 10^{5} \mathrm{sec}$ (approx. 7 days) at $1453^{\circ} \mathrm{K}\left(1180^{\circ} \mathrm{C}\right)$. The concentration amplitude was reduced to $\pm 0.08 \mathrm{Ti}$ compared to the model predictions of \pm 0.08 or \pm 0.02 Ti depending on the diffusion coefficient used. $^{6}$ Perfect agreement exists for $\mathrm{D}=1.4 \times 10^{-10}$ $\mathrm{cm}^{2} / \mathrm{sec}$. A second sample, HT 94888, was also homogenized as above. $\mathrm{C}_{\mathrm{A}}$ was reduced from approximately \pm 0.3 to $\pm 0.05 \mathrm{Ti}$. Comparison with
TABLE 3. Diffusion Data for Ti in Gamma Iron ${ }^{3}$

\begin{tabular}{|c|c|c|c|c|}
\hline MATRIX & $\begin{array}{c}\text { Temperature } \\
\left({ }^{\circ} \mathrm{C}\right)\end{array}$ & $\begin{array}{c}\mathrm{D}_{\mathrm{O}} \\
\left(\mathrm{cm}^{2} / \mathrm{sec}\right)\end{array}$ & $\begin{array}{c}\mathrm{Q} \\
\text { (kcal/mole) }\end{array}$ & Author \\
\hline Gamma Fe & $1160-1320$ & 0.15 & 60 & Moll \\
\hline Gamma Fe & $1150-1300$ & $8.5 \times 10^{3}$ & 90 & Swisher \\
\hline
\end{tabular}

TABLE 4. Calculated Titanium Variation for Various Diffusion Coefficients and Bar Sizes After Homogenization at $1180{ }^{\circ} \mathrm{C}$

$\mathrm{D}=1.4 \times 10^{-10} \mathrm{~cm}^{2} / \mathrm{sec}:$

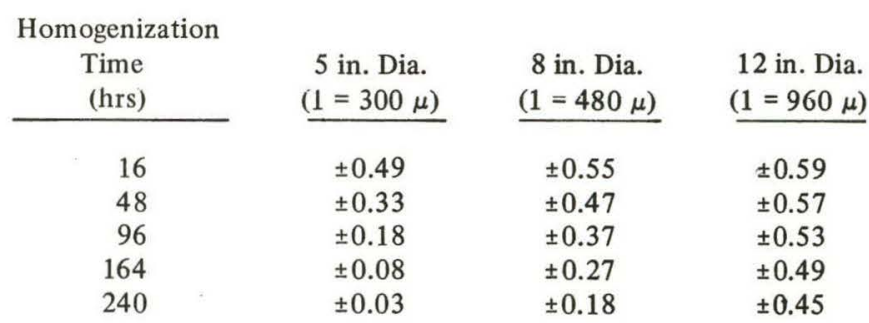

$\mathrm{D}=2.43 \times 10^{-10} \mathrm{~cm}^{2} / \mathrm{sec}:$

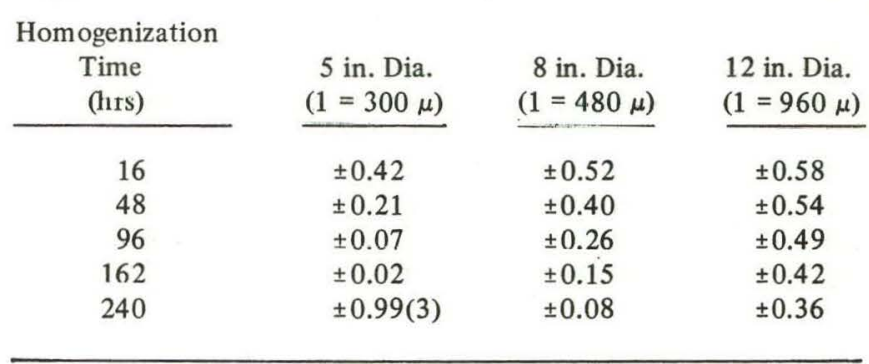

the calculated value of $\pm 0.04 \mathrm{Ti}\left(\mathrm{D}=1.4 \times 10^{-10}\right.$ $\mathrm{cm}^{2} / \mathrm{sec}$ ) shows that the model yields good first order agreement between predicted and experimental results.

When comparing the model's predictions with experimental results, it must be recognized that microprobe measurements are subject to variation because of sampling location and orientation in the bar or ingot. For example, two different sampling locations in Heat 7683 showed a wide spread in Ti concentration amplitude; \pm 0.2 vs. \pm 0.45 . See Table 1. Further work to characterize this variability will be done. 


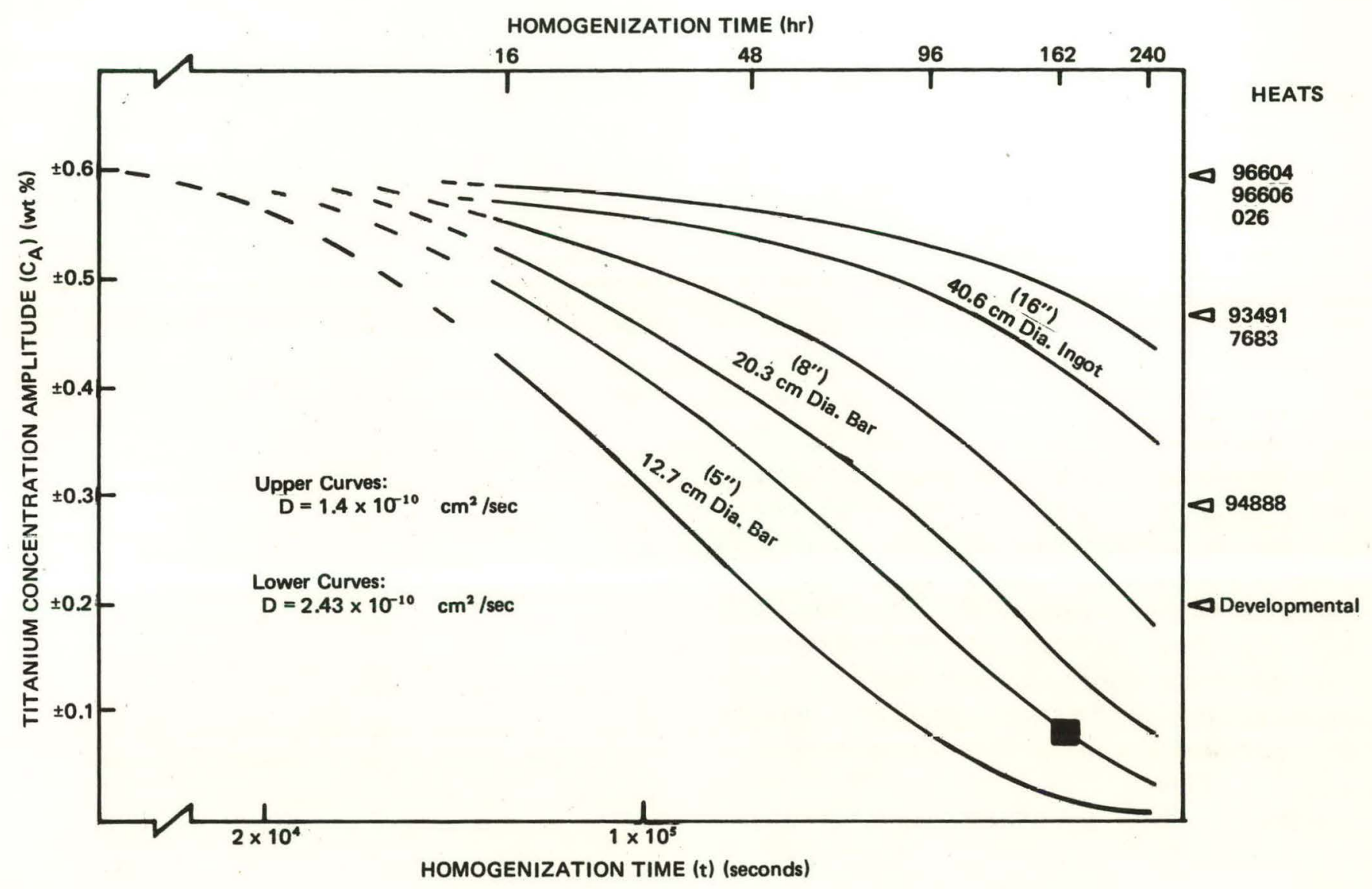

FIGURE 23. Predicted Ti Segregation After Homogenizing at $1180{ }^{\circ} \mathrm{C}$ for Three Different Product Diameters. Also included is the experimental point ( $\bullet$ ) for Heat 926 which was homogenized at $12.7 \mathrm{~cm}$ for 164 hours at $1180{ }^{\circ} \mathrm{C}$. 
TABLE 5. Tensile Properties of "Standard" and Super Homogenized JBK-75, Heat 926. All tensiles were solution treated at $1020^{\circ} \mathrm{C}, 1 \mathrm{hr}$, W.Q., and aged at $720^{\circ} \mathrm{C}, 16$ hours.

\begin{tabular}{|c|c|c|c|c|c|c|c|c|c|}
\hline & \multicolumn{2}{|c|}{$0.2 \%$ Yield Strength } & \multicolumn{2}{|c|}{$\begin{array}{c}\text { Ultimate } \\
\text { Tensile Strength }\end{array}$} & \multirow{2}{*}{$\begin{array}{c}\text { Total } \\
\text { Elong. } \\
(\%)\end{array}$} & \multirow{2}{*}{$\begin{array}{c}\text { Uniform } \\
\text { Elong. } \\
(\%)\end{array}$} & \multirow{2}{*}{$\begin{array}{l}\text { RA } \\
(\%)\end{array}$} & \multicolumn{2}{|c|}{$\begin{array}{l}\text { Fracture } \\
\text { Strength }\end{array}$} \\
\hline & $\left(\mathrm{MN} / \mathrm{m}^{2}\right)$ & (ksi) & $\overline{\left(\mathrm{MN} / \mathrm{m}^{2}\right)}$ & (ksi) & & & & $\left(\mathrm{MN} / \mathrm{m}^{2}\right)$ & (ksi) \\
\hline Super Homogenized & 637.0 & 92.4 & 1091 & 157.3 & 27.6 & 24.8 & 40.9 & 1647 & 238.9 \\
\hline As-Received & 712.8 & 103.4 & 1108 & 160.8 & 24.7 & 22.5 & 33.2 & 1574 & 228.4 \\
\hline
\end{tabular}

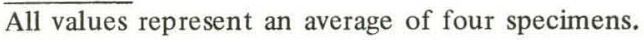

Tensiles were orientated in a radial direction in the $12.7-\mathrm{cm}$ ( 5 in) diameter bar stock at the mid-radius position.

Reducing the Ti band spacing, L, before homogenization appears to be the most effective technique to improve the efficiency of the homogenization treatment. This is shown by the equation:

$$
\mathrm{t}=\mathrm{L}^{2} / \pi^{2} \mathrm{D}(18)
$$

where $t$ is the time to reach $1 / \mathrm{e}$ of the initial concentration amplitude, $\mathrm{C}_{\mathrm{A}}$. A two-fold reduction in segregation wavelength would result in a fourfold decrease in homogenization time. As discussed earlier, band spacing may be reduced through better melting procedures. Another viable technique would be to draw down the ingot to a smaller diameter, thus reducing $\mathrm{L}$, prior to the homogenization treatment. Still another technique would be to increase $\mathrm{D}$ (via raising the homogenization temperature $1180^{\circ} \mathrm{C}$ ). However, this cannot be done because it is already close to the hot short temperature range for the alloy.

Increasing homogenization time, $t$, would improve homogeneity. Reviewing the curves in Figure 23, it appears that combining a draw down prior to homogenizing with increased time would significantly reduce segregation. For example, homogenizing a $20.3-\mathrm{cm}$ diameter bar for 96 hours would reduce the $\mathrm{Ti}_{\mathrm{A}}$ nearly $50 \%$. Since vendors are not confident about their ability to refine the grain size in subsequent draw down to $12.7-\mathrm{cm}$ diameter, the long time treatment would have to be given at a larger diameter; i.e., $25.4 \mathrm{~cm}$ or $30.5 \mathrm{~cm}$ or prior to final forging at $15.2-\mathrm{cm}, 12.7-$ $\mathrm{cm}$, and $3.2-\mathrm{cm}$ diameters. In the latter case, substantial grain refinement will have to occur during the forging operation. Forgings will be made to evaluate this option.
In summary, homogenizing at the ingot stage will be ineffectual in reducing the observed Ti segregation because of the wide band spacing. Reducing the spacing by draw down prior to homogenizing coupled with longer homogenization times can significantly reduce the segregation and is, therefore, recommended. Since a fine grain size is required in the $12.7-\mathrm{cm}$ diameter bar (required for ultrasonic inspection) it appears that homogenization would have to be accomplished prior to 20.3$\mathrm{cm}$ diameter. Other techniques to reduce $\mathrm{Ti}$ segregation amplitude and band spacing may be accomplished through changes in arc melting parameters. This possibility is currently being reviewed by the vendors.

The effect of homogeneity on solution treated $\left(1020^{\circ} \mathrm{C}, 1 \mathrm{hr}\right.$ W.Q.) and aged $\left(720^{\circ} \mathrm{C}, 16 \mathrm{hr}\right)$ tensile properties is currently being determined. Initial results on Heat 926 which was tested in the "standard" $(\Delta \mathrm{Ti}= \pm 0.6)$ and the super homogenized $(\Delta \mathrm{Ti}= \pm 0.08)$ conditions showed that tensile properties are affected as shown in Table 5. For the super homogenized condition, yield strength dropped by approximately $10 \mathrm{ksi}$ and ductility (\% RA) increased by $7.7 \%$. Although a limited number of tensile samples were tested (4 per condition), there appears to be a significant improvement in property variability. The fracture surfaces, reviewed via SEM, showed a duplexed fracture morphology orientated in bands which presumably correspond to the high and low $\mathrm{Ti}$ bands in the material. See Figure 24. The homogenized samples showed no directionality; however, localized areas did appear to be intergranular in nature. See Figure 25. The fracture 


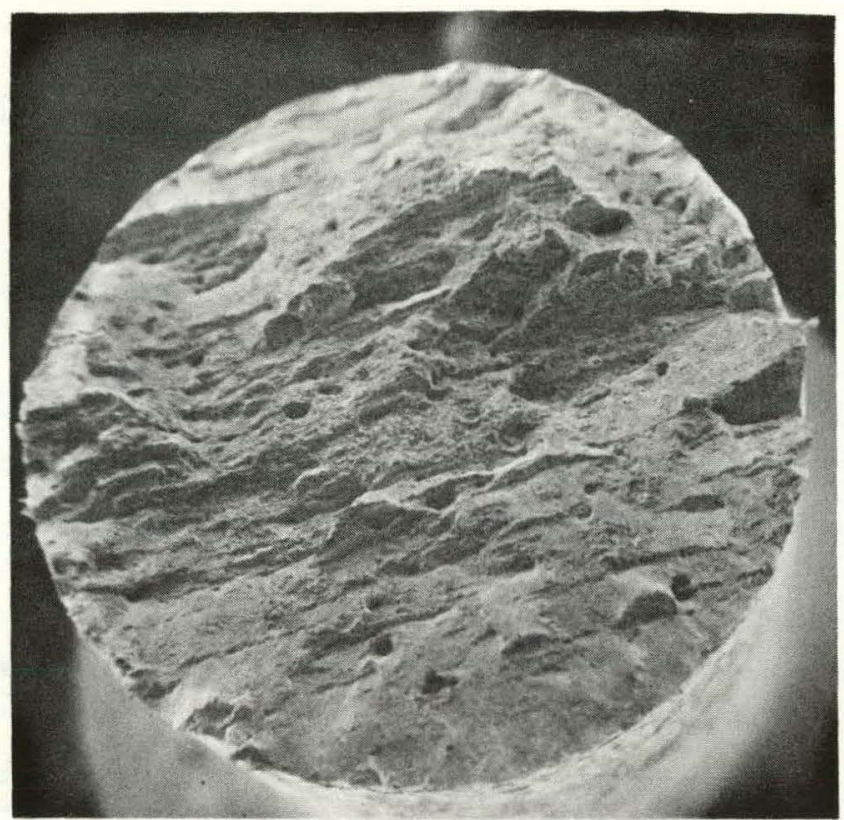

(a)

$28 X$

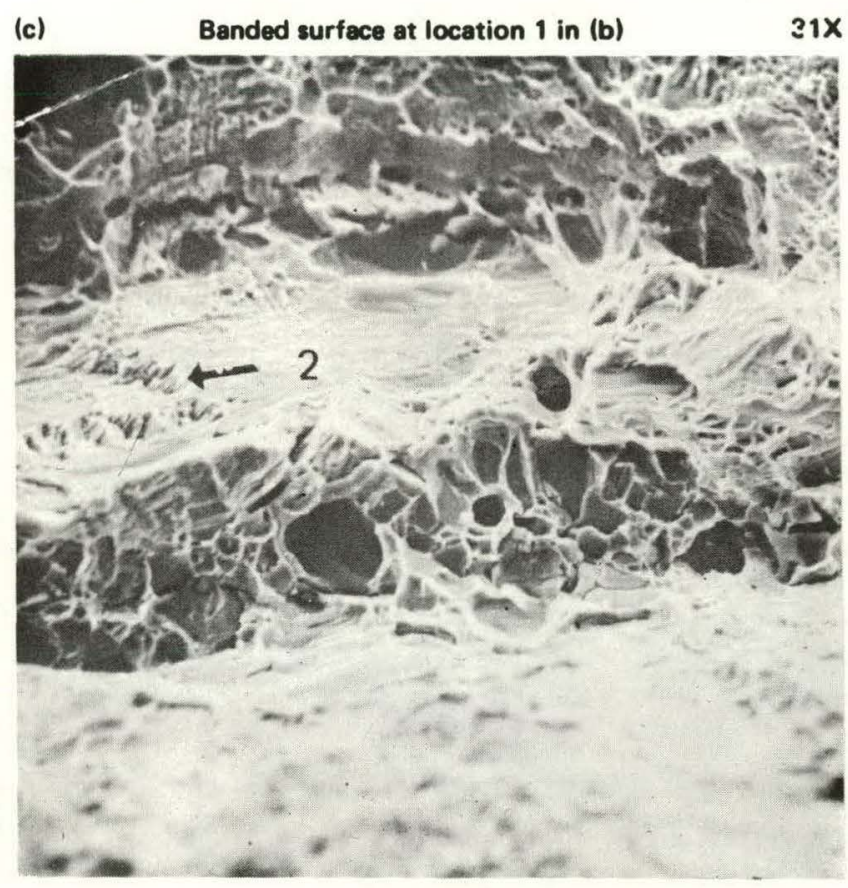

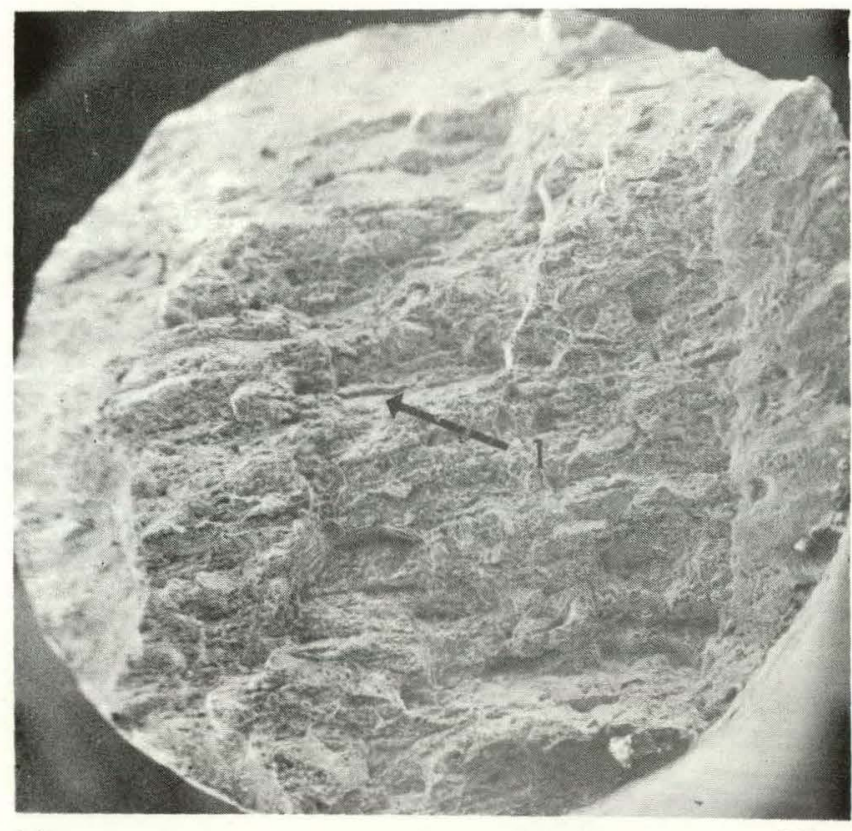

(b)

$750 x$

FIGURES 24(a), (b), (c), and (d). SEM Photographs of Two Different Tensile Fractures From Heat 926, "Standard", Showing Striations Which Correspond in Orientation to the Titanium Banding (a) and (b). Higher magnification shows duplexed nature of the fracture morphology (c) and apparent cellular eta phase (d). Tensiles were solution treated and aged. 

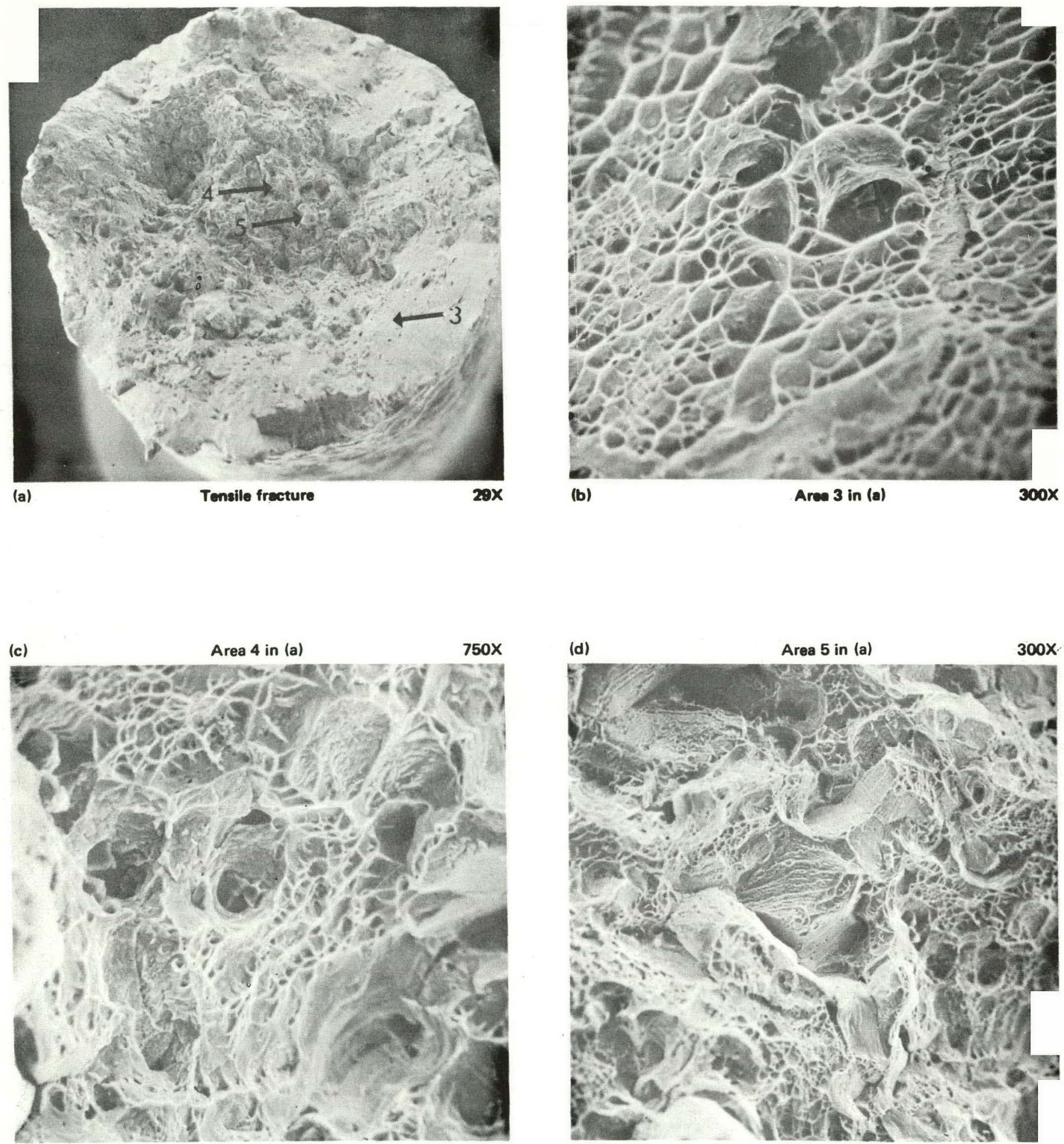

FIGURES 25(a), (b), (c), and (d). SEM Photographs of a Tensile Fracture From Heat 926, Super Homogenized, Showing an Absence of Striations (see Figure 24) in (a). Local areas showed shallow dimples (b), deep dimples (c), and intergranular (d) fracture morphologies. The material is in the solution treated and aged condition. 


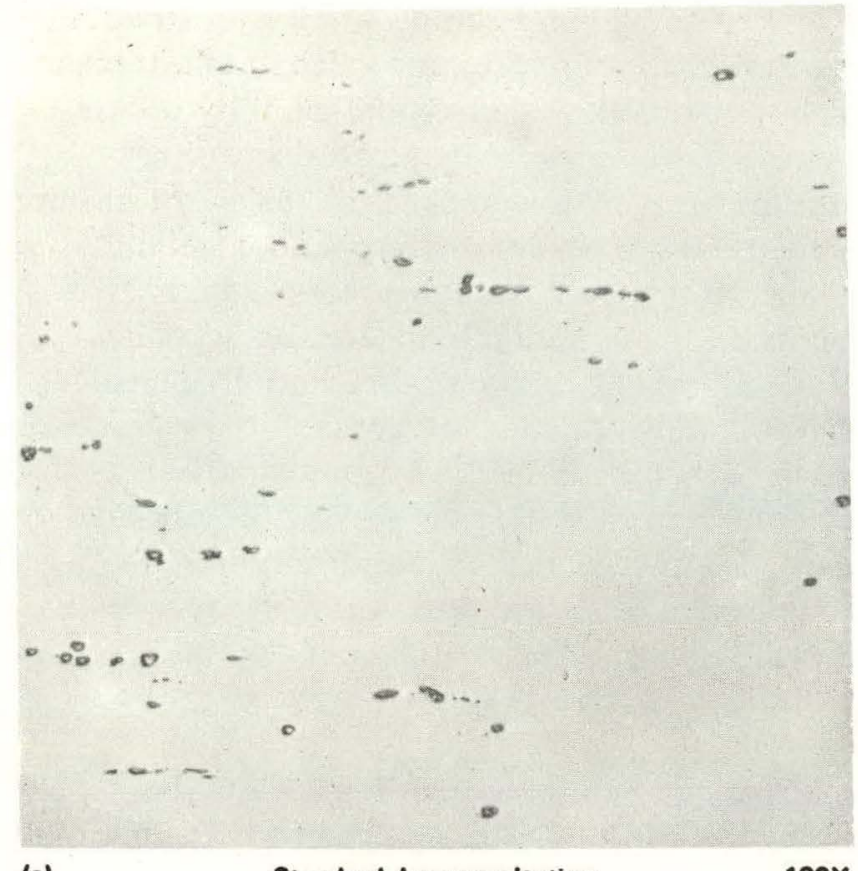

(a)

Standard homogenization

$100 x$
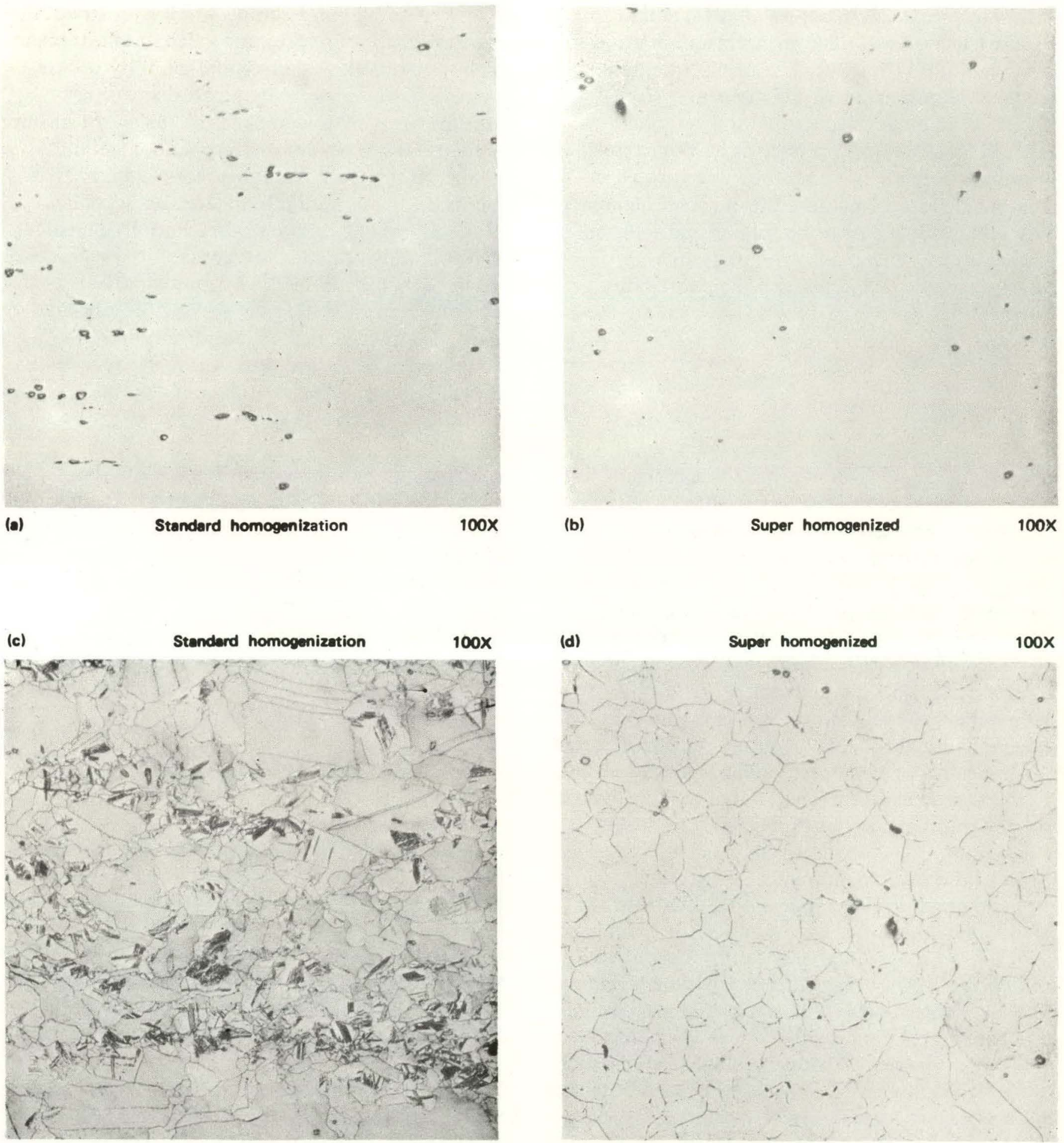

FIGURES 26(a), (b), (c), and (d). Photomicrographs of Heat 926 in the Standard and Super Homogenized Conditions Showing the Effect of Homogenization on Ti Inclusion Stringers and Eta Banding. Both samples were solution treated $\left(1020^{\circ} \mathrm{C}, 1 \mathrm{hr}\right.$, W.Q.) and aged $\left(720{ }^{\circ} \mathrm{C}, 16 \mathrm{hr}\right)$. 
surfaces were polished and reviewed on end as shown in Figure 26. Samples in the standard condition showed carbide stringers and in some cases bands of cellular eta identically orientated to the bands observed on the fracture surface. The super homogenized sample showed only random carbides with no trace of eta. As explained elsewhere in this report, eta may be expected in segregated material because the eta solvus temperature is increased to near the forging and solution temperatures. In summary, homogeneity appears to affect tensile properties and their variability. Further testing is being done to substantiate these findings.

\section{SUMMARY}

Microprobe analysis shows that there is significant titanium segregation in different JBK-75 heats. Segregation of titanium is described in terms of one sigma standard deviation from the measured mean value. Values of sigma for the 5-inch diameter experimental heats are of the order of $0.10 \mathrm{wt} \%$ Ti. Within this range, it is generally accepted that there would be a high confidence that the alloy chemistry is relatively uniform, representing acceptable product. However, sigma values as large as $0.30 \mathrm{wt} \% \mathrm{Ti}$, in larger production ingots, are indicative of extreme titanium segregation and, in this case, could be expected to dramatically affect many critical properties of the alloy.

Segregation of titanium in JBK-75 product has been an uncontrolled variable since observed titanium distributions vary significantly from heat to heat. Heats of material with different titanium distributions will behave differently on a microscale. It is the contention of this report that the observed titanium segregation in JBK-75 can also affect important macroscale properties of the alloy. For example, banding is known to influence mechanical properties and forgeability of certain alloys. Lack of product uniformity, which can't be controlled within a desired range, will contribute to variability in subsequent product quality.

It appears that banding plays a major role in the forgeability of JBK-75. Numerous forging defects have been encountered in JBK-75, especially at high strain rates associated with HERFing. In addition to lower forging temperatures and higher strain rates, segregation may also promote adiabatic shear planes. In alloys like JBK-75, maximum ductility occurs over a specific temperature range, decreasing at both the high and low ends of the range. At higher temperatures, incipient melting is a controlling factor. At lower temperatures, loss in ductility is due to the precipitation of deleterious second phases like eta or carbides. In addition, increased segregation reduces the hot workability range; i.e., region of maximum ductility. In fact, severe segregation can significantly narrow the working range. Improved chemical uniformity in JBK-75 would widen this range, thus avoiding the necessity of maintaining extremely tight controls in production processing.

In alloys that exhibit extreme strain rate sensitivity during hot working, it is important to develop some type of forgeability test to evaluate starting stock. The two different tests described in this report are initial attempts to devise a simple test to determine forgeability of incoming bar stock. Initial success of these tests hold promise in that we will have a good method for evaluating the relationship between chemical segregation, formation of forging defects and forgeability of JBK-75.

A basic model for titanium diffusion in JBK-75 has been described which relates band spacing and homogenization treatment. Experimental results indicate that the model gives a good first order approximation on the relationship between homogenization and the magnitude of titanium segregation in typical product. The model shows that prior work to reduce band spacing before homogenization is effective in reducing segregation. It also predicts that homogenizing the ingot produces little change in the segregation and this is verified by experience.

Segregation is typically controlled by reducing melt rates in the VAR process and/or utilizing an effective homogenization treatment. Reducing the VAR ingot diameter is also an option but is not considered viable because of poor metal recovery. Reducing the melt rate is attractive; however, melting practice cannot be controlled by a procurement specification. Improvements in melting can only be accomplished through the cooperation of the vendor. Extending 
the homogenization time suffers from two disadvantages. First, if done at a breakdown size such as 8-inch square, it is not compatible with maintaining acceptable grain size for ultrasonic inspection of bar stock. Secondly, the economics of long homogenization treatments are not popular with vendors. Although homogenization of intermediate product has been shown to be extremely effective in reducing segregation, several barriers would have to be surmounted before this could be an acceptable production process.

Microprobe analysis has shown that typical JBK-75 product from large production ingots contain extreme variations in the distribution of titanium. Such banding can affect important properties and performance of the alloy and may explain many of the problems experienced in developing IBK-75 processes. From a better understanding of the chemical, uniformity of the product, it should be possible to determine if segregation can adversely affect mechanical properties in forgings. Work in this area is continuing. In addition, establishing a correlation between segregation and forgeability will provide the opportunity to improve process controls. Minimizing chemical variability will provide the best possible JBK-75 product for program applications.

\section{REFERENCES}

1. R. S. Culver, "Thermal Instability Strain in Dynamic Plastic Deformation" in Metallurgical Effects at High Strain Rates, p. 519-530, AIME, Plenum Press, New York, NY, 1973.

2. J. G. Sevillano, et al., Scripta Met., 1977, Vol. II, p. 581.

3. P. S. Mathur and W. A. Backofen, Met. Trans., 1973, Vol. 4, p. 643.

4. M. E. Backman and S. A. Finnegan, "Propagation of Adiabatic Shear" in Metallurgical Effects at High Strain Rates, pp. 531-544, AIME, Plenum Press, New York, NY, 1973.
5. G. Malaprade, et al., Scripta Met., 1973, Vol. 12, p. 1083.

6. R. N. Orava and H. E. Otto, Journal of Metals, February 1970, p. 2429.

7. P. C. J. Gallagher, Met. Trans., Vol. 1, September 1970, p. 2429.

8. A. Viollan, Scripta Met., 1973, Vol. 7, p. 867.

9. R. E. Bailey, Metals Engineering Quarterly, May 1975, p. 43.

10. A. M. Sabroff, et al., Forging Materials and Practices, pp. 253-293, Reinhold Book Corp., New York, NY, 1968.

11. R. H. Kane, "Structure and Hot Workability of AISI Type 310 Stainless Steel," The Hot Deformation of Austenite, AIME, New York, NY, 1977, p. 457.

12. Metals Handbook, 5 th Ed., Vol. 1, ASM, 1961, p. 509.

13. A. M. Sabroff, et al., Forging Materials and Practices, p. 258, Rcinhold Book Corp., New York, NY, 1968.

14. Ibid, p. 271

15. Ibid, p. 256.

16. W. Yeniscavich, "Joining," The Superalloys, p. 525, John Wiley and Sons, New York, NY, 1972.

17. R. E. Reed-Hill, Physical Metallurgy Principles, p. 252, D. Van Nostrand Company, Inc., 1964.

18. G. R. Prudy and J. S. Kirkaldy, Metallurgical Transactions $A$, 1971, Vol. 2, p. 371.

19. Diffusion Data, 1969, Vol. 3, p. 141. 
RFP-2925 